\title{
Mechanism of Fire Prevention with Liquid Carbon Dioxide and Application of Long-Distance Pressure-Holding Transportation Technology Based on Shallow Buried and Near-Horizontal Goaf Geological Conditions
}

\author{
Naifu Cao $\mathbb{1}^{1,2,3}$ and Yuntao Liang ${ }^{2,3}$ \\ ${ }^{1}$ China Coal Research Institute, Beijing 100013, China \\ ${ }^{2}$ State Key Laboratory of Coal Mine Safety Technology, Fushun 113122, China \\ ${ }^{3}$ CCTEG Shenyang Research Institute, Fushun 113122, China
}

Correspondence should be addressed to Naifu Cao; caonaifu@syccri.com

Received 1 February 2021; Accepted 4 May 2021; Published 12 May 2021

Academic Editor: Mohamed Azaroual

Copyright $(92021$ Naifu Cao and Yuntao Liang. This is an open access article distributed under the Creative Commons Attribution License, which permits unrestricted use, distribution, and reproduction in any medium, provided the original work is properly cited.

\begin{abstract}
Shallow burial, very close coal seam groups, and spontaneous combustion are typical characteristics of most coal seams in the Shendong mining area, China. With the continuous extension of the production level of various mines, some mining areas have gradually shown complex production conditions including multiple types of fire forms such as those in coal fields, small kilns, and multilayer mined-out and hidden high-temperature areas, resulting in fire control difficultly and posing threats to safety. With the aim of limiting the above problems, in this work, the liquid carbon dioxide fire prevention technology is focused on. Phase change and migration law of $\mathrm{CO}_{2}$ in the goaf are studied. Through the study on the influence of the use of liquid $\mathrm{CO}_{2}$ on the cooling law of high-temperature coal and on its spontaneous combustion characteristics and through thermal analysis experiments, it was observed that the porosity of loose coal has a significant impact on the cooling effect of carbon dioxide. Moreover, it was emphasized that the higher the $\mathrm{CO}_{2}$ concentration, the higher the rise in temperature of coal oxidation, and the increase of $\mathrm{CO}_{2}$ concentration was able to affect apparent activation of coal oxidation, leading to a theoretical basis to explain the effect of $\mathrm{CO}_{2}$ in inhibiting coal spontaneous combustion. The utilization of Fluent numerical modeling allowed us to simulate the diffusion radius of liquid $\mathrm{CO}_{2}$ injected into the goaf, to study the effective inerting radius of liquid $\mathrm{CO}_{2}$ on the left coal in the goaf. After comprehensive analysis of experiments and numerical simulations, appropriate equipment and process flow are selected and designed. Taking the Huojitujing well of Daliuta Coal Mine in Shendong mining area as the industrial test site, an intelligent pressure-holding transportation of liquid $\mathrm{CO}_{2}$ in the $1000 \mathrm{~m}$ transportation pipeline was developed. The surface liquid $\mathrm{CO}_{2}$ infusion capacity was $20 \mathrm{t} / \mathrm{h}$, and the pressure-holding interval at the end of the transportation pipeline was determined to be 1.0-2.3 MPa. The maximum diffusion radius of the mined-out area is $300 \mathrm{~m}$ under the effect of positive air flow and self-expansion and diffusion of $\mathrm{CO}_{2}$ gas in the roadway. Under the influence of reverse wind flow and self-expansion and diffusion, the diffusion

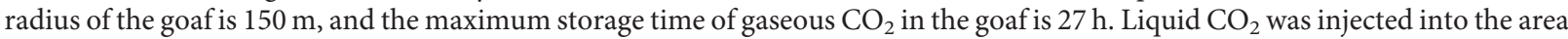
with relevant presence of $\mathrm{CO}$, an indicator of possible fires. Practice has proved that, after 65 hours and two perfusion processes, the $\mathrm{CO}$ concentration dropped from $790 \mathrm{ppm}$ to $41 \mathrm{ppm}$, which indicates that liquid $\mathrm{CO}_{2}$ has a significant effect on fire prevention.
\end{abstract}

\section{Introduction}

Fire prevention is one of the most important research topics in the field of coal mine safety in China. At present, technologies for the prevention of spontaneous combustion such as the use of inert gas, grouting, gel injection, and mine resistance are widely utilized. However, each technology has its specific range of application conditions and limitations [1]. For example, the use of nitrogen injection limits issues related to heat development [2]. On the other hand, nitrogen 
can diffuse, and leaks problems can be present [3]. Liquid nitrogen can easily freeze in the goaf, and the cost of this process is high. Long characteristic times of slurry transport in the grouting technology and small grouting diffusion radius limit the effect of this technology in achieving largescale coverage of the goaf [4]. The temperature reduction range upon glue injection is small, and the spontaneous combustion fire cannot be effectively controlled. Due to the concealment of spontaneous combustion and fire location, the conventional glue injection cannot accurately reach the fire source location. Short inhibition times characterize the use of an inhibitor agent [5]. Through relevant research and tests in recent years, it has been seen that liquid $\mathrm{CO}_{2}$ can be utilized to prevent spontaneous combustion in the goaf, with advantages related to $\mathrm{CO}_{2}$ low temperature and inert properties. The $\mathrm{CO}_{2}$ density is high, the gas can stay in the goaf for a long time, and the inerting time is relatively long. Coal can adsorb $\mathrm{CO}_{2}$, and this can effectively prevent the contact between $\mathrm{O}_{2}$ and coal itself [6]. Therefore, compared with traditional fire prevention technology, the one based on the use of $\mathrm{CO}_{2}$ has advantages that deserve further investigation.

In this paper, through experimental research, numerical simulation, technological equipment design, and field test, the phase change and migration law of $\mathrm{CO}_{2}$ in the goaf are addressed, and the technology of fire prevention through the use of liquid $\mathrm{CO}_{2}$ is developed. Field tests are guided by aspects concerning fluid mechanics, heat transfer, chemical reaction kinetics, and field measured data, based on the characteristics of the shallow burial and the near-level superlarge goaf in the Shendong mining area, China, selected as a case study.

\section{Rationale of the Research Project}

Most of the main coal seams in the Shendong mining area have the typical characteristics of shallow burial, short distance coal seams, easy spontaneous combustion, and so on [7]. According to the actual conditions of coal seams in various mining areas, Shenhua Group has carried out exploration work for the construction and production of superlarge mines. With the continuous extension of the production level of various mines, some mining areas have gradually shown complex production conditions where multiple types of fires form. The coexistence of fires in different locations and of hidden areas characterized by high temperature makes fire management more difficult and poses threats to mine production safety.

The development of pores and fissures of coal samples in the Shendong mining area at different magnifications is shown in Figures 1-3.

From the scanning electron microscope (SEM) images, it can be found that there are different porosities or crack structures on the surface of the coal samples. The width of the pores and cracks is basically at the micron level; however, the degree of crack development changes from sample to sample. The charcoal striped silk structure can be seen at 3000x magnification, leading to a large specific surface area. At $20000 x$, it is seen that the coal samples have fully developed pores and good connectivity between the pores. Micron-scale cracks are fully developed as well, and cracks and pores are interconnected. In the scanned image at $70000 x$, it can be seen that the surface is rough. The specific surface area changes from sample to sample, as it is related to the development of pores and cracks. This causes differences in the amount of adsorbed oxygen and strongly affects the early oxidation and the consequent coal spontaneous combustion. If there are more pores and cracks and a larger specific surface area, there are more opportunities for the contact of coal with oxygen, thus leading to early oxidation and heat release. Therefore, from the perspective of the influence of the porous microstructure on oxygen adsorption, the experimental coal samples investigated here show tendency to spontaneous combustion.

\section{Experimental Study}

\subsection{Experimental Methods}

3.1.1. Experiments on Coal Cooling. These experiments were carried out with the aid of a self-made device system for program temperature rising (Figure 4). The experimental apparatus includes air intake, heating, monitoring, gas collection and detection systems, and a coal sample tank (Figure 5). A constant flow of air is introduced. The air is provided by an air pump and pressed into a $1.5 \mathrm{~m}$ copper pipe for preheating, so that the air temperature is close to the ambient value. The temperature of the coal sample is measured by a thermocouple placed in the coal sample tank and connected to a temperature inspection instrument. The temperature of the coal sample is increased to $170^{\circ} \mathrm{C}$ at a constant heating rate (starting from $30^{\circ} \mathrm{C}$ ). The air enters the coal sample tank. The coal sample reacts, and the generated gas is sent to a gas chromatograph for concentration analysis.

The height of the steel-made coal sample tank is $20 \mathrm{~cm}$, and the bottom diameter is $8 \mathrm{~cm}$. The upper and lower parts of the coal sample tank are equipped with glass fibers to reduce heat loss. After removing the oxide layer from the surface of the coal sample, the coal sample is crushed and divided into five particle sizes: $0-0.9,0.9-3,3-5,5-7$, and $7-10 \mathrm{~mm}$. The mass of each coal sample is $1000 \mathrm{~g}$. Before the test, each sample was vacuum-dried at $40^{\circ} \mathrm{C}$ for 12 hours to reduce the influence of moisture on coal heating and carbon dioxide cooling. Three thermocouples (1\#, 2\#, and $3 \#$ in Figure 5) are located, respectively, at $15 \mathrm{~cm}, 10 \mathrm{~cm}$, and $5 \mathrm{~cm}$ from the bottom of the coal sample tank, to measure the temperature distribution in space. Coal samples are loaded into the tank until the height of the sample exceeds the 1\# measuring point. At the beginning of the test, the temperature detector is turned on and the $2 \#$ measuring point is used as reference. The coal sample is heated at a rate of $0.4^{\circ} \mathrm{C} /$ min. The air flow rate is maintained at $120 \mathrm{~mL} / \mathrm{min}$, to simulate natural coal oxidation. Air is pumped until the temperature of the coal body reaches $170^{\circ} \mathrm{C}$. The temperature rise is then stopped, and the maximum temperature is maintained for 10 minutes. At the same time, the air intake system is closed to minimize heat loss. Subsequently, liquid 
$\mathrm{CO}_{2}$ is injected in the upper part of the coal sample tank (gas outlet zone) at injection pressure of $0.3 \mathrm{MPa}$ and with mass flow rate of $0.15 \mathrm{~g} / \mathrm{s}$; it flows out through the gas inlet in the lower part of the coal sample tank. The temperature changes in time upon $\mathrm{CO}_{2}$ cooling are measured, until the temperature of the 3 measuring points is lower than the spontaneous combustion characteristic temperature of the samples; at this point, the cooling experiment ends [9].

3.1.2. Experiments on the Influence of $\mathrm{CO}_{2}$ on Coal Spontaneous Combustion. The concentration of $\mathrm{CO}$ generated upon coal oxidation and the oxygen consumption rate for coal samples are here used as indicators in order to analyze the influence of different $\mathrm{CO}_{2}$ concentrations on the spontaneous combustion characteristics of coal [10]. The device for these experiments is the same as the one shown in Figures 4 and 5. Experiments have been designed to conduct tests on coal spontaneous combustion under different atmosphere conditions, to study the influence of $\mathrm{CO}_{2}$ on the critical temperature and on the dry cracking temperature of selected coal samples [11]. Five coal samples of different particle size, $200 \mathrm{~g}$ each, were mixed to form a $1000 \mathrm{~g}$ coal sample that was loaded into the tank. During the heating process, the heating rate was $0.3^{\circ} \mathrm{C} / \mathrm{min}$ and the air supply flow rate was $120 \mathrm{~mL} / \mathrm{min}$. When the temperature of the coal sample increased by $10^{\circ} \mathrm{C}$, gases were extracted for quantitative analysis. The initial temperature of the experiment was set at $T=30^{\circ} \mathrm{C}$, and the maximum temperature during the experiment was limited to $T=170^{\circ} \mathrm{C}$. The experimental conditions are shown in Table 1: experiment no. 1 was carried out in atmosphere simulating air composition, but experiments nos. 2, 3, and 4 under progressively increasing $\mathrm{CO}_{2}$ concentration (from 33.3 to $78.8 \%$ by volume), while $\mathrm{O}_{2}$ and $\mathrm{N}_{2}$ concentrations progressively decreased $\left(\mathrm{O}_{2}\right.$ from $15 \%$ to $3 \%$, balance $\mathrm{N}_{2}$ ).

3.1.3. Experiments on the Gaseous $\mathrm{CO}_{2}$ Adsorption by Coal Samples. A coal sample with mass of $500 \mathrm{~g}$ and particle size of $60-80$ mesh $(0.18-0.25 \mathrm{~mm})$ was selected, evenly placed in a tube furnace and sealed. Before the experiment, the coal sample was heated and degassed at a temperature of $25^{\circ} \mathrm{C}$ for 1 hour. After degassing, the tube furnace was evacuated to an absolute pressure of zero with a vacuum pump. At this time, gaseous $\mathrm{CO}_{2}$ was injected into the tube furnace until the pressures of $0.1,0.2$, and $0.3 \mathrm{MPa}$ were reached, respectively, with temperatures of 30,40 , and $50^{\circ} \mathrm{C}$, respectively. The pressure value in the tube furnace was recorded at regular intervals until the pressure no longer changed for all practical purposes. The change in pressure in the tube furnace indirectly reflects the $\mathrm{CO}_{2}$ adsorption by coal at different temperatures and pressures.

The test rig is represented and illustrated in Figure 6. A pressure reducing valve, a pressure stabilizing valve, and a control valve, namely 3, 7, and 10 valves in Figure 6, are sequentially connected between the high-pressure $\mathrm{CO}_{2}$ Dewar and the gas pipeline. The coal sample tube is made of quartz, being high-temperature resistant, compact, and visible, with two openings at both ends. The left and right ends can be sealed by flanges, sealing rings, sealing caps with holes, and valves. The gas buffer tank can stabilize the gas source and provide the required gas. The temperature adjustment range of the heating device is from room temperature to $1200^{\circ} \mathrm{C}$. A thermocouple made of corundum is arranged in the heating device. The pressure sensor gas is arranged next to the gas buffer tank and the coal sample pipe and is connected to the computer for real-time monitoring.

\subsubsection{Thermal Analysis Experiments. A HITACHI} STA7200RV synchronous thermal analysis instrument was used. A 200 -mesh $(0.075 \mathrm{~mm})$ coal sample was vacuumdried at constant temperature of $40^{\circ} \mathrm{C}$ for 24 hours, and then $10 \mathrm{mg}$ was selected for the experiment. The air flow rate in the instrument was $50 \mathrm{~mL} / \mathrm{min}$. After maintaining a constant temperature of $30^{\circ} \mathrm{C}$ and letting the system thermally stabilize, the temperature is increased at a heating rate of $10 \mathrm{~K} /$ min up to $900^{\circ} \mathrm{C}$, and the differential scanning calorimetry (DSC) curve of the coal sample under four different atmosphere conditions (the same as those reported in Table 1) is measured, to investigate the effect of $\mathrm{CO}_{2}$ on heat release and oxidation kinetics.

\subsection{Experimental Results}

3.2.1. Experiments on Coal Cooling. For the low-temperature oxidation stage, the critical temperature and dry cracking temperature of coal are of great significance [12]. The critical temperature of coal refers to the first temperature at which the coal-oxygen recombination reaction is accelerated and the rate of oxygen consumption consequently increases. Dry cracking temperature refers to the second temperature at which coal-oxygen recombination accelerates. Figure 7 reports the distribution of the proportions of temperature drops, as measured by the three thermocouples indicated in Figure 5, for samples of different particle size and as a function of the stage of the process. We here define "first stage" as that from the beginning of the cooling process down to the maximum dry cracking temperature $\left(130^{\circ} \mathrm{C}\right)$. The proportion changes from $15 \%$ to $18 \%$ (at decreasing particle size with little effect of this parameter) as measured by thermocouple $1 \#$, from $8 \%$ to $13 \%$ (at decreasing particle size with moderate effect of this parameter) as measured by thermocouple $2 \#$, and from $11 \%$ to $21 \%$ (at decreasing particle size with marked effect of this parameter) as measured by thermocouple 3\#. Namely, both the role of particle size and the relevance of the percentage value increase when going from bottom to top (Figure 5). The "second stage" is that from the highest dry cracking temperature $\left(130^{\circ} \mathrm{C}\right)$ down to the highest critical temperature $\left(80^{\circ} \mathrm{C}\right)$. The cooling time in the second stage is the longest, and the proportion is larger at finer particle size for all the three temperature measuring ports. The "third stage" is that from the highest critical temperature down to the end of the experiment. It takes longer for measuring point $2 \#$ and is affected by particle size as the proportion is now larger for larger particle size [13]. 


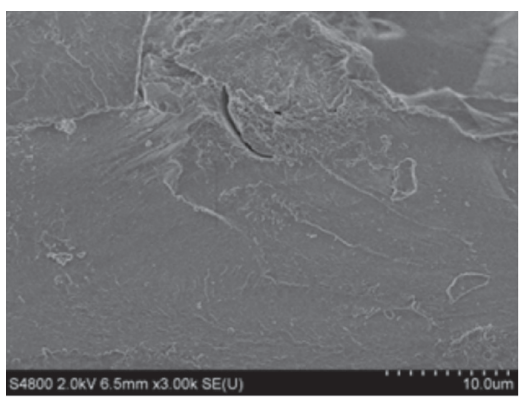

(a)

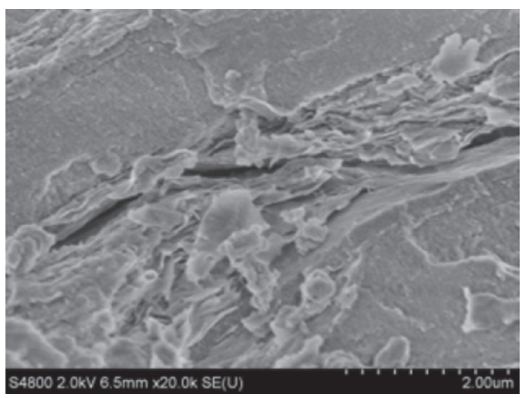

(b)

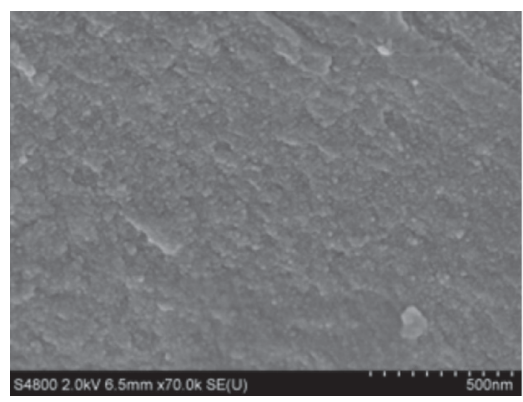

(c)

Figure 1: SEM images of samples in Bulianta Coal Mine at different magnifications (3000, 20000, and 70000x from left to right).

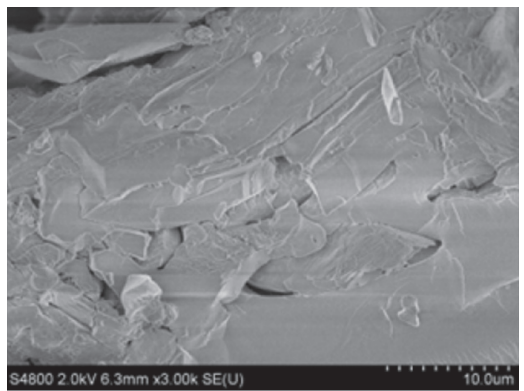

(a)

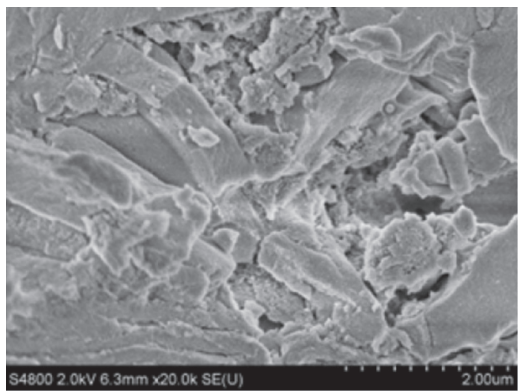

(b)

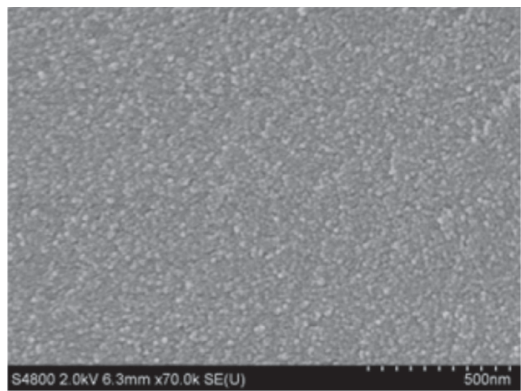

(c)

FIgURE 2: SEM images of samples in Shigetai Coal Mine at different magnifications (3000, 20000, and 70000x from left to right).

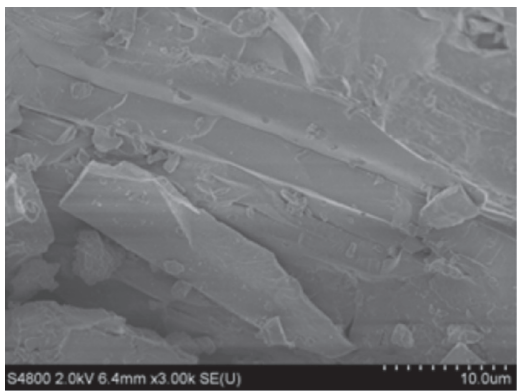

(a)

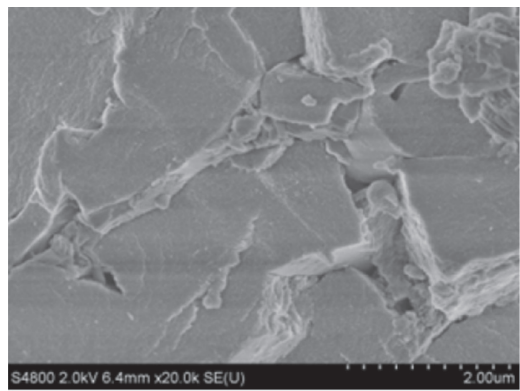

(b)

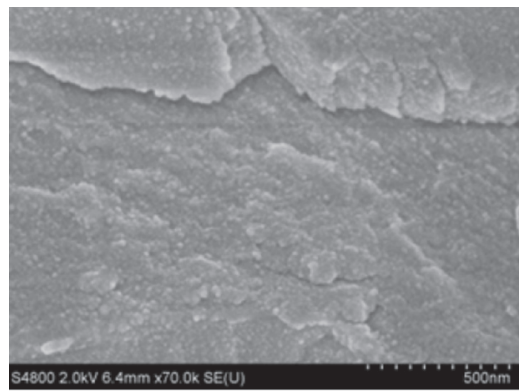

(c)

Figure 3: SEM images of samples in Wanli Coal Mine at different magnifications (3000, 20000, and 70000x from left to right).

Explanation of these trends is that, as the particle size of the coal sample increases, the specific surface area decreases, and the coal-oxygen contact area is relatively reduced, thereby reducing the rate of coal-oxygen recombination reaction and gradually increasing the critical temperature $\left(80^{\circ} \mathrm{C}\right)$ and dry cracking temperature $\left(130^{\circ} \mathrm{C}\right)$ of the coal body. It is in fact observed that the most relevant stage is the third for coarser particles and the second for finer ones.

3.2.2. Experiments on the Influence of $\mathrm{CO}_{2}$ on Coal Spontaneous Combustion. Figure 8 shows the evolution of $\mathrm{CO}$ concentration as a function of coal particle temperature under the four different atmospheres listed in Table 1. CO concentration increases with particle temperature and decreases at increasing $\mathrm{CO}_{2}$ concentration (from the maximum value of about $8000 \mathrm{ppm}$ when $\mathrm{CO}_{2}$ is absent, to about $3000 \mathrm{ppm}$ when $\mathrm{CO}_{2}$ is present at an amount of $78.8 \%$ in the atmosphere). The differences among cases at different $\mathrm{CO}_{2}$ concentration are more and more significant after $110^{\circ} \mathrm{C}$. The high concentration of $\mathrm{CO}_{2}$ can inhibit the reaction process between coal and $\mathrm{O}_{2}$, resulting in a decrease in the amount of oxidized gas $(\mathrm{CO})$ produced.

It can be seen from Figure 9 that the oxygen consumption rate of the coal sample increases with the coal temperature and with the increase of the oxygen concentration in the carrier gas during the oxidation heating process. The maximum value is of more than $3000 \mathrm{~mol} /\left(\mathrm{cm}^{3}\right.$ s) when $\mathrm{O}_{2}$ 


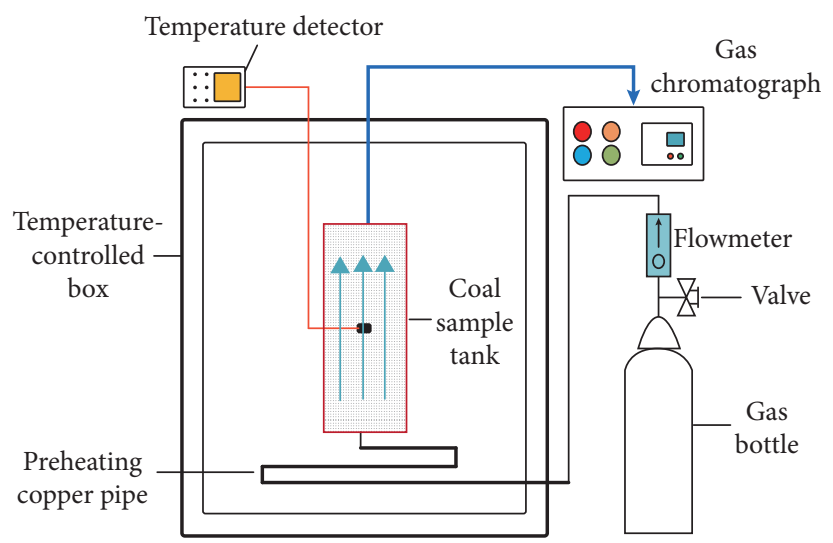

Figure 4: Scheme of the experimental system [8].

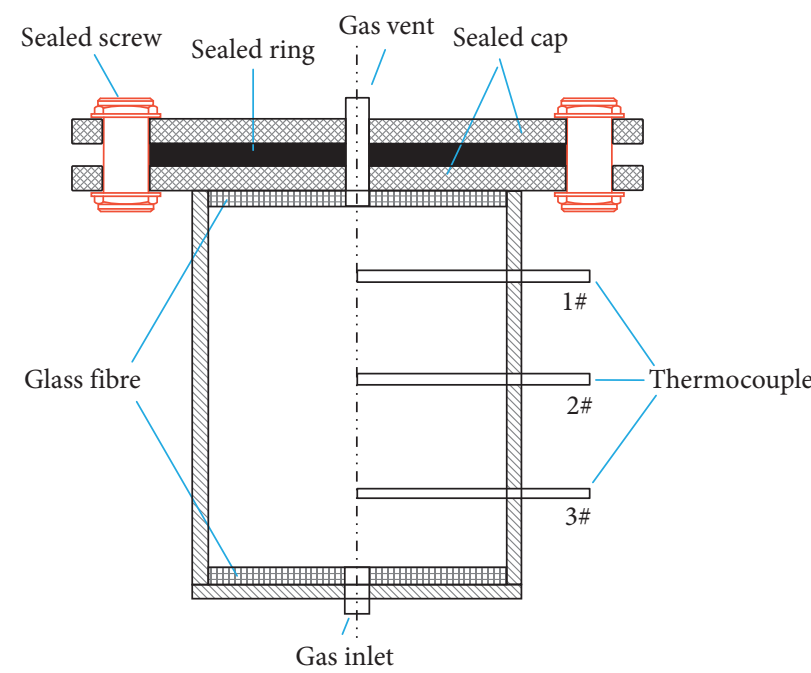

FIGURE 5: Details of the self-made coal sample tank.

concentration is $21 \%$, but less than $500 \mathrm{~mol} /\left(\mathrm{cm}^{3} \mathrm{~s}\right)$ when $\mathrm{O}_{2}$ concentration is $3 \%$ only (positive effect of the presence of $\mathrm{CO}_{2}$ ). As a matter of fact, due to the different adsorption capacity of coal with respect to different gaseous species, the adhesion capacity of $\mathrm{CO}_{2}$ on the surface of coal molecules is much higher than that of other gases. During coal oxidation [14], the coal particle adsorbs $\mathrm{CO}_{2}$ faster than $\mathrm{O}_{2}$. This is because the surface of coal has a large number of different functional groups, and the ether and carbonyl groups can easily provide electrons to $\mathrm{CO}_{2}$ to form a complex, which is widely distributed in the pores of the coal. In addition, the increase in $\mathrm{CO}_{2}$ concentration also inhibits the redox reaction of aromatic hydrocarbons in coal molecules, resulting in more aromatic functional groups being better retained [15]. Moreover, $\mathrm{CO}_{2}$ inhibits the oxidation activity of more active functional groups in coal molecules, resulting in increasing the apparent activation energy of coal molecular reactions [16]. In other words, $\mathrm{CO}_{2}$ can be better adsorbed in coal particle pores, occupying the pores that should have adsorbed oxygen. This leads to the slowing down of the reaction between coal and oxygen.
3.2.3. Experiments on the Gaseous $\mathrm{CO}_{2}$ Adsorption by Coal Samples

Effect of temperature. Figure 10 illustrates the time-pressure drop trends in the tube furnace as a function of temperature, for three subcases where the $\mathrm{CO}_{2}$ pressure has been fixed. The adsorption of $\mathrm{CO}_{2}$ by coal is an exothermic dynamic equilibrium process. Increasing the adsorption temperature causes the adsorption equilibrium to move in the (unwanted) direction of desorption. Therefore, at increasing $T$, the $\mathrm{CO}_{2}$ adsorption capacity of the test coal sample gradually decreases, the pressure drop in the tube furnace decreases, and the adsorption saturation state is reached earlier. In addition, there is a time effect on gas adsorption. An increase in $T$ can increase the activity of adsorbed gas molecules and reduce the time the adsorbed gas stays on the surface of coal pores, thereby reducing the amount of adsorption. Furthermore, the higher the $\mathrm{CO}_{2}$ pressure is, the earlier the adsorption saturation is reached. The occurrence of adsorption was mainly concentrated before $10 \mathrm{~h}$, and the pressure drop changed little in the later period of the test. At 
TABLE 1: Atmosphere composition for tests on the influence of $\mathrm{CO}_{2}$ concentration (\% by volume).

\begin{tabular}{lccc}
\hline Experiment & $\mathrm{O}_{2}(\%)$ & $\mathrm{N}_{2}(\%)$ & $\mathrm{CO}_{2}(\%)$ \\
\hline 1 & 21 & 79 & 0 \\
2 & 15 & 51.7 & 33.3 \\
3 & 9 & 30 & 61 \\
4 & 3 & 18.2 & 78.8 \\
\hline
\end{tabular}

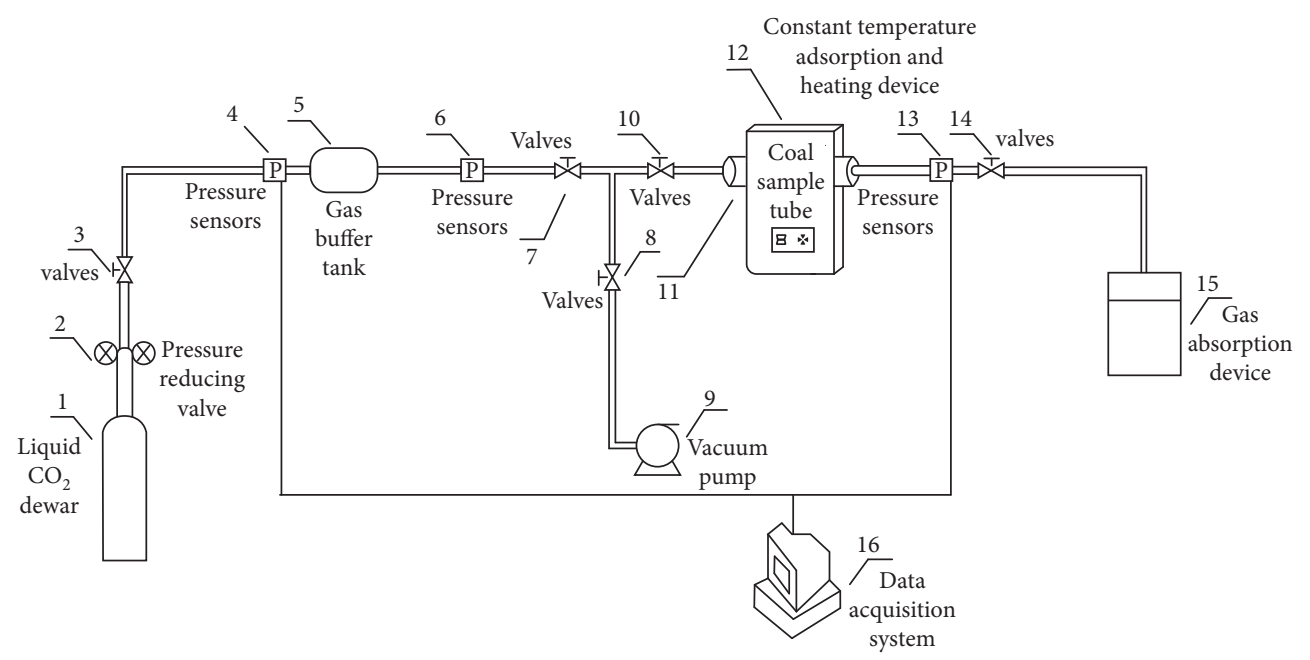

Figure 6: Scheme of the $\mathrm{CO}_{2}$ adsorption experimental device.

the same time, the pressure drop in the tube furnace tends to rise after $24 \mathrm{~h}$, as at long times the sample begins to desorb $\mathrm{CO}_{2}$ due to little increases in $T$, but this is a very minor effect as it can be seen in Figure 10.

Effect of $\mathrm{CO}_{2}$ pressure. Figure 11 illustrates the timepressure drop trends in the tube furnace as a function of $\mathrm{CO}_{2}$ pressure, for three subcases where the temperature has been fixed. At a given value of $T$, as the pressure of $\mathrm{CO}_{2}$ increases, the pressure drop in the tube furnace changes more significantly, as the number of adsorbate molecules entering the coal pores increases, and the probability of contact with the coal surface increases as well. When the amount of adsorbed gas is higher, a decrease of the pressure drop in the tube furnace is observed. Recalling the concept of mean free path, at fixed $T$, higher pressure can cause shorter mean free path and less marked irregular thermal motion for gaseous molecules, and gradual increase of gas adsorption by coal. In addition, at fixed $T$, the higher the $\mathrm{CO}_{2}$ pressure is, the earlier the saturation state of adsorption is reached (i.e., higher pressure promotes adsorption). On the other hand, at fixed $\mathrm{CO}_{2}$ pressure, higher temperature inhibits the process as already discussed.

3.2.4. Thermal Analysis Experiments. DSC can be used to study the physical and chemical changes of coal during heating and oxidation. The area subtended to the DSC endothermal or exothermal peak is proportional to the change in enthalpy. Therefore, DSC can be used to quantitatively evaluate the heat change.

Figure 12 illustrates the DSC results obtained under the four different atmosphere conditions listed in Table 1.
Table 2 shows the peak temperature and maximum DSC value under experimental conditions 1-4 listed in Table 1. The lower the $\mathrm{CO}_{2}$ concentration, the steeper the DSC curve and the higher the peak value: this indicates a more intense exothermic oxidation reaction when the $\mathrm{CO}_{2}$ concentration is lower. On the other hand, the presence of $\mathrm{CO}_{2}$ progressively suppresses coal oxidation. Because coal has a relatively good capacity to adsorb $\mathrm{CO}_{2}$, it is easy for $\mathrm{CO}_{2}$ to cover the surface of the coal particle to form a protective film against $\mathrm{O}_{2}$, thus reducing the oxidation rate. In addition, the formation of the protective film inhibits heat release. The coal sample and the surrounding environment need to reach a high temperature to melt the protective film. As the concentration of $\mathrm{CO}_{2}$ increases, the apparent activation energy of coal oxidation increases as well. This is because the actual oxidation rate will be reduced due to the addition of $\mathrm{CO}_{2}$, and the coal oxidation exothermal peak will be accordingly reduced.

\section{Numerical Simulation Analysis}

The reference model is geometrically depicted in Figure 13. The basic model parameters are listed in Table 3. The lower end of the intersection line between the working face and the goaf area and the side wall of the air intake lane is the origin of the coordinate system for establishing the geometric model in Figure 13. The length of the working face is along the $x$ axis, and the depth of the goaf is along the $y$ axis. The height of the goaf is along the $z$ axis [17]. Table 4 illustrates values of properties of model materials, and Table 5 shows the boundary control conditions. 


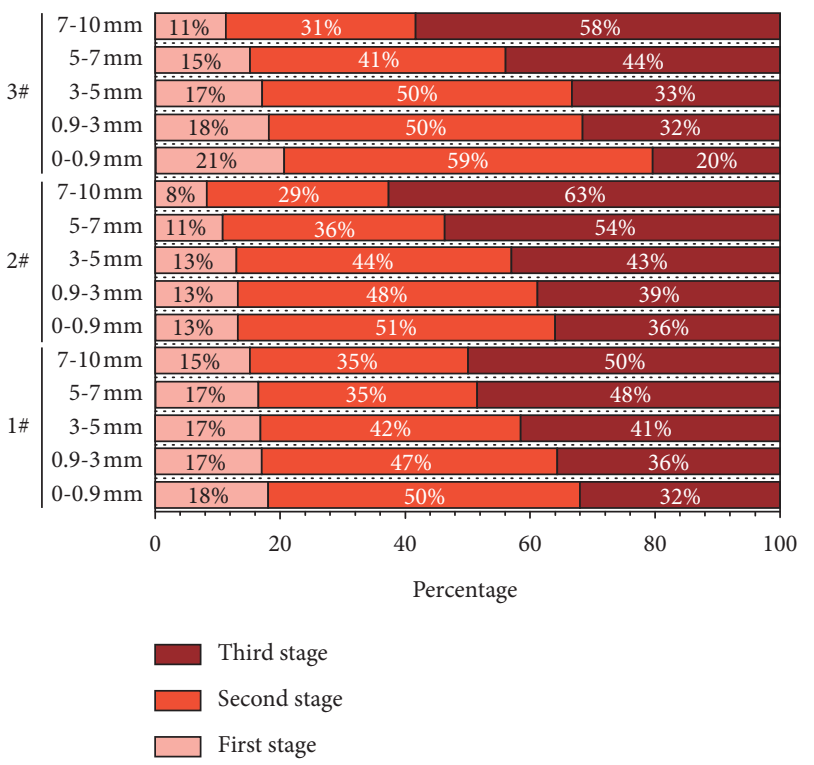

Figure 7: Distribution of proportions of temperature drops, as measured by thermocouples 1\#, 2\#, and 3\# (Figure 5), during cooling of coal samples with different particle sizes. The process is subdivided into three stages as described in the text [8].

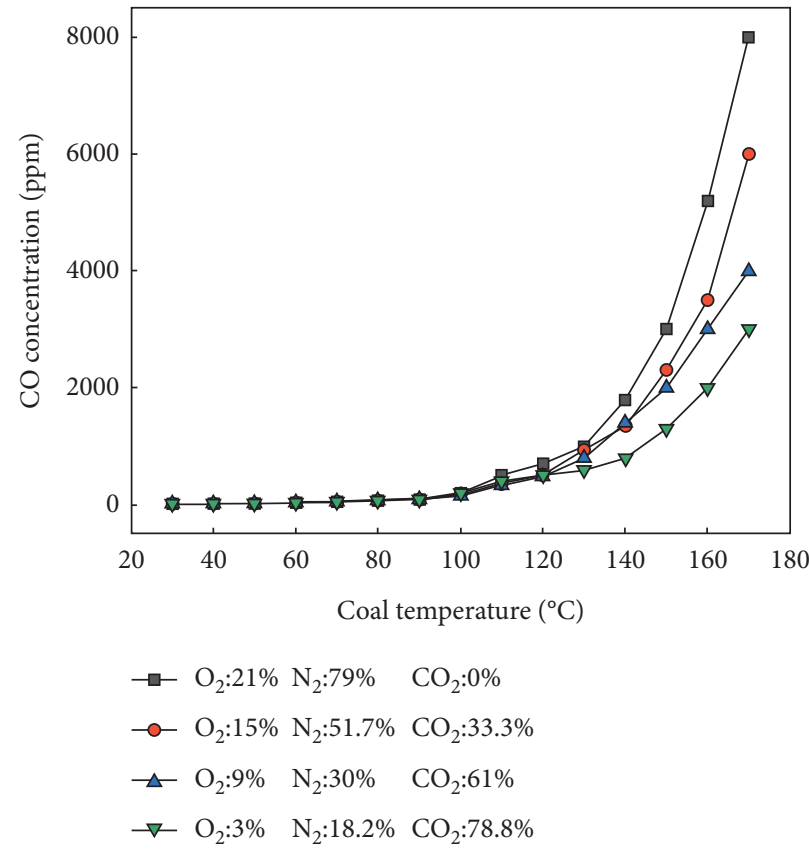

FIGURE 8: CO concentration as a function of coal temperature for experimental conditions 1-4 (Table 1).

ANSYS Fluent 15 fluid dynamics software is utilized to simulate the seepage and gas concentration fields in the goaf, to examine the $\mathrm{CO}_{2}$ and $\mathrm{O}_{2}$ concentration fields before and after the injection of $\mathrm{CO}_{2}$ in the goaf, and to investigate the characteristic parameters of inerting and cooling, in order to determine the degree of influence of $\mathrm{CO}_{2}$ deposition. Through model establishment, grid division and parameter setting, numerical calculation, result processing, and other steps, the impact of key injection parameters on the diffusion of $\mathrm{CO}_{2}$ in the goaf during $\mathrm{CO}_{2}$ injection is analyzed. Taking liquid carbon dioxide injection for 2 hours as an example, the diffusion characteristics of $\mathrm{CO}_{2}$ in the goaf are analyzed in the case of different buried depths of release ports and $\mathrm{CO}_{2}$ injection flow rates.

The transient solver embedded in Fluent simulation software is used to calculate the cooling and diffusion characteristics of $\mathrm{CO}_{2}$ in the goaf. Model results are illustrated in Figure 14. It can be seen that, after the $\mathrm{CO}_{2}$ is released from 


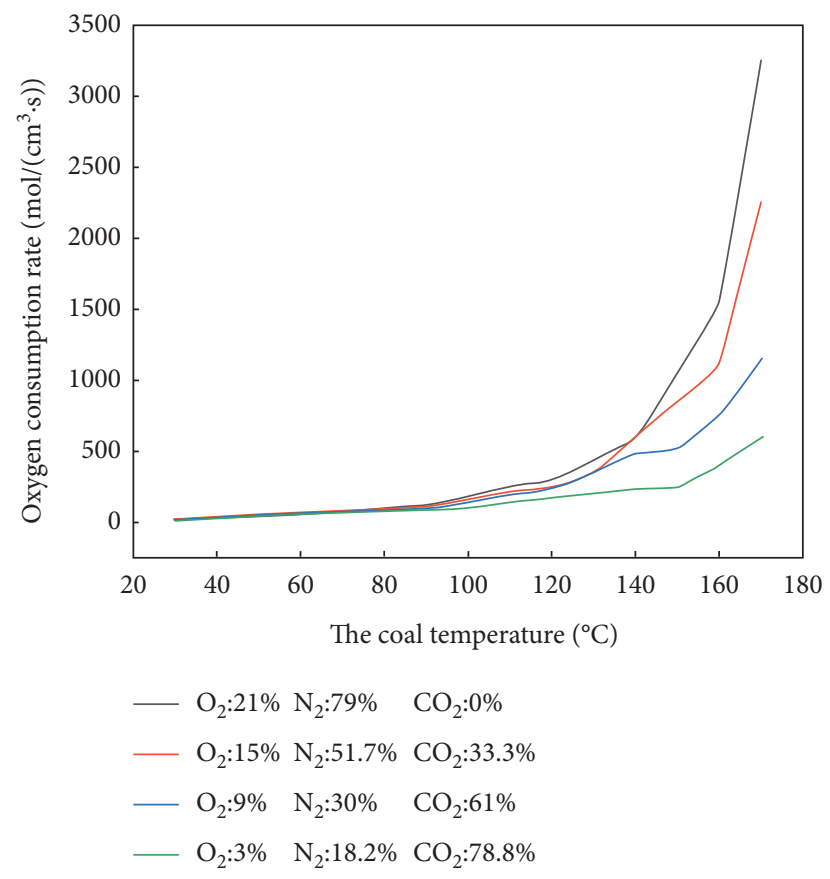

FIgURE 9: Oxygen consumption rate as a function of coal temperature for experimental conditions 1-4 (Table 1).

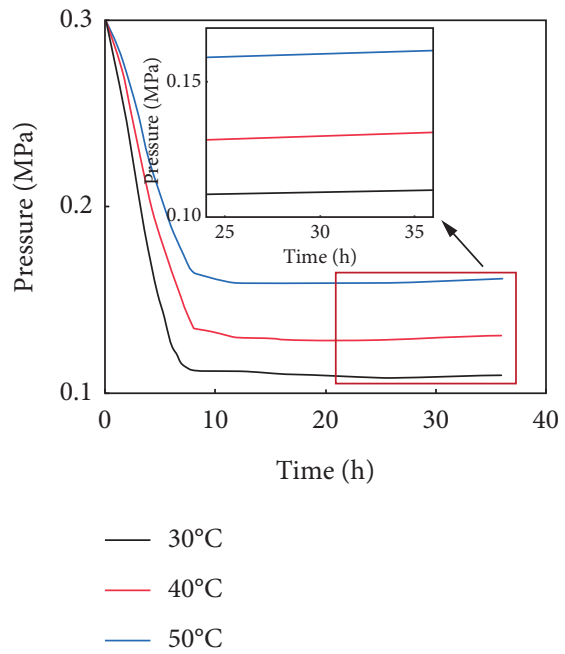

(a)
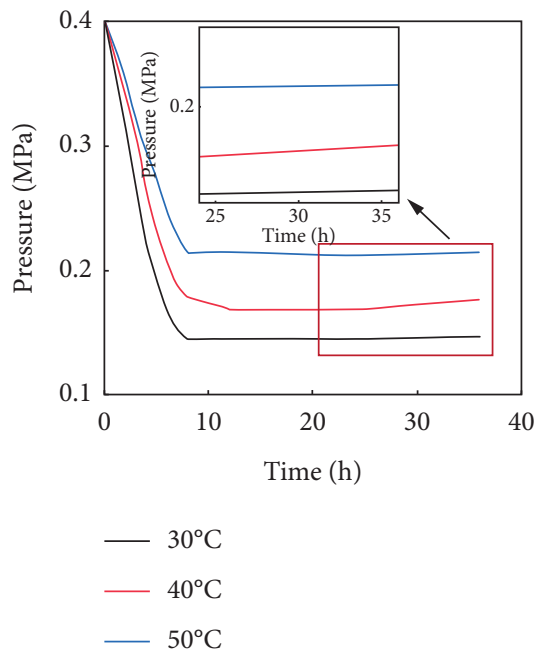

(b)

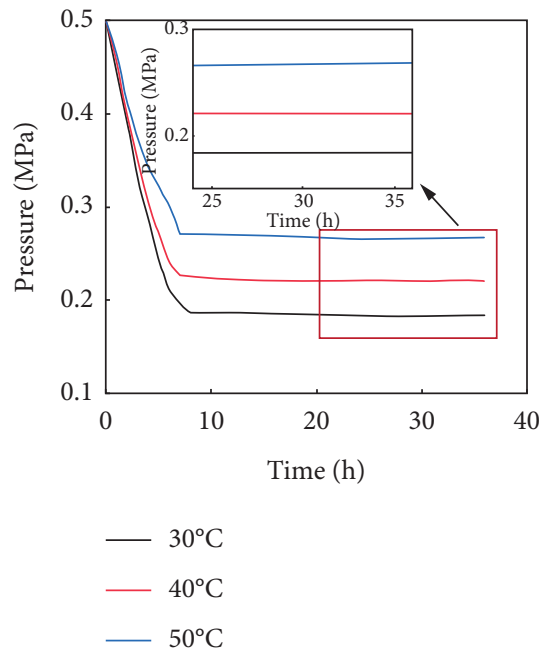

(c)

Figure 10: Pressure drop in the tube furnace vs. time at temperature varying from $30^{\circ} \mathrm{C}$ to $50^{\circ} \mathrm{C}$ at $\mathrm{CO}_{2}$ pressure of (a) $0.3 \mathrm{MPa}$, (b) $0.4 \mathrm{MPa}$, and (c) $0.5 \mathrm{MPa}$ upon $\mathrm{CO}_{2}$ adsorption.

the release port in the goaf, it rapidly diffuses around under the action of pressure or concentration gradient. As the injection time increases from 2 to $6 \mathrm{~h}$, the $\mathrm{CO}_{2}$ diffusion area in the goaf gradually expands. Due to the dilution effect of the fresh air flow on the inlet side, the diffusion of the concentration of $\mathrm{CO}_{2}$ in the goaf is uneven. At $2 \mathrm{~h}$, the diffusion volume with a volume fraction of $\mathrm{CO}_{2}$ greater than $10 \%$ reaches $1284.7 \mathrm{~m}^{3}$. At $6 \mathrm{~h}$, this value increases to $4154.4 \mathrm{~m}^{3}$. This confirms that $\mathrm{CO}_{2}$ diffuses very quickly in the goaf and can have a very good inerting effect [18].

\section{Process of Surface Liquid $\mathrm{CO}_{2}$ Direct Injection}

The schematic diagram of the process proposed here is shown in Figure 15. The system mainly consists of electric regulating valve, liquid $\mathrm{CO}_{2}$ storage tank truck, booster device, flow control valve, instrumentation, DN50 stainless steel liquid $\mathrm{CO}_{2}$ transmission pipeline, intrinsically safe mine monitoring substation, integrated control terminal, and optical cable for mine communication. 


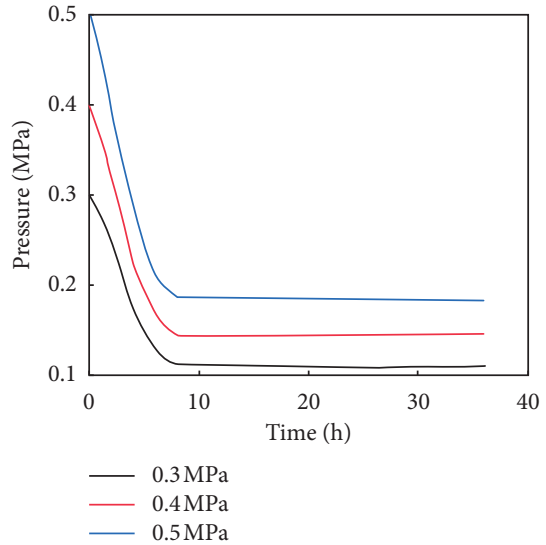

(a)

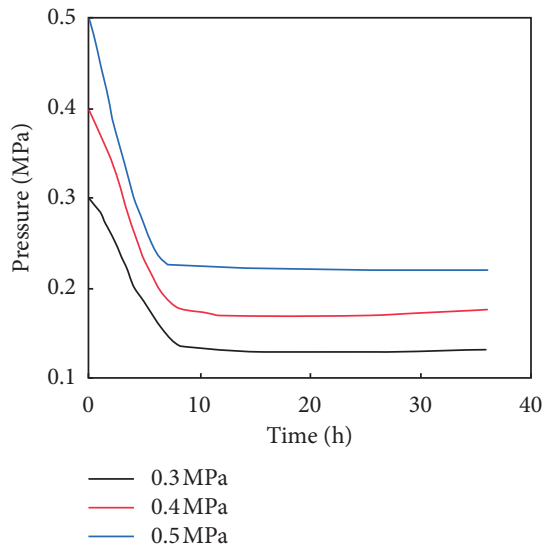

(b)

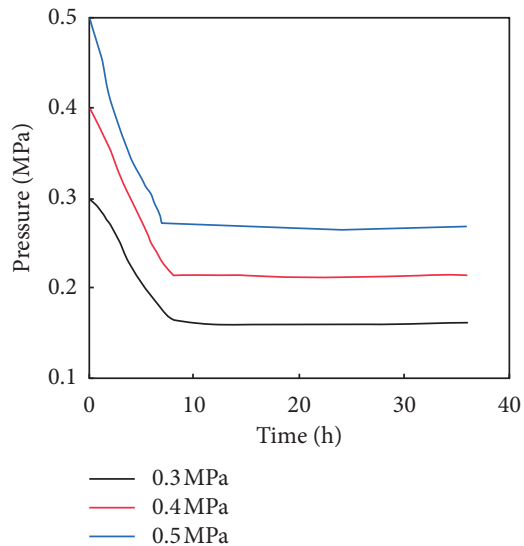

(c)

Figure 11: Pressure drop in the tube furnace vs. time at $\mathrm{CO}_{2}$ pressure varying from 0.3 to $0.5 \mathrm{MPa}$ at nominal temperature of (a) $30^{\circ} \mathrm{C}$, (b) $40^{\circ} \mathrm{C}$, and (c) $50^{\circ} \mathrm{C}$ upon $\mathrm{CO}_{2}$ adsorption.

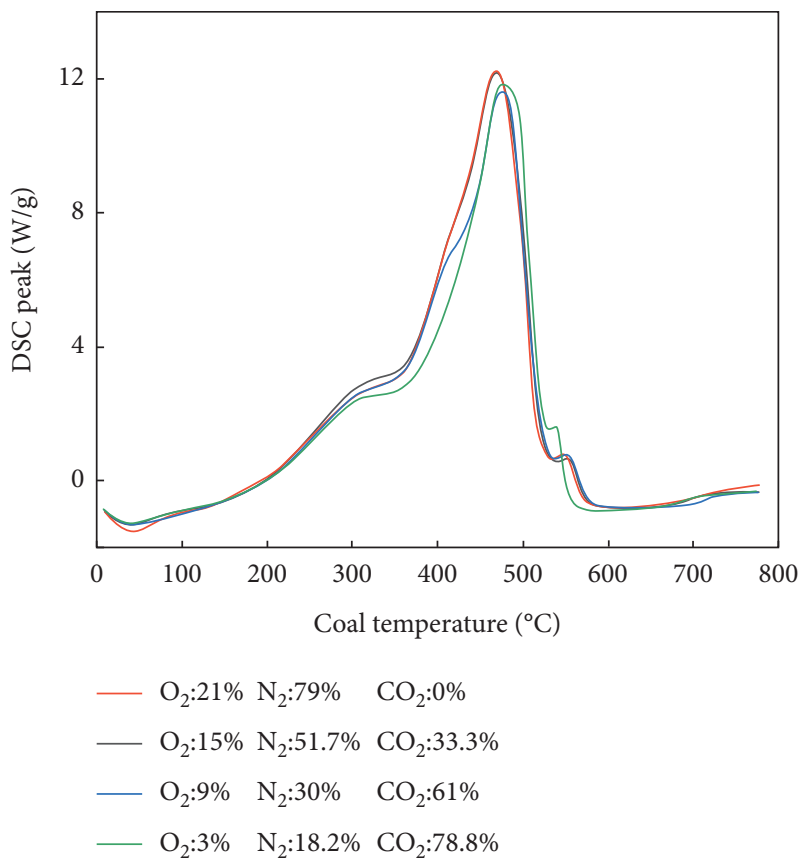

FIgURE 12: DSC results for coal oxidation under experimental conditions 1-4 (Table 1).

Metal hoses are utilized to connect the gas phase and liquid phase of the liquid $\mathrm{CO}_{2}$ tanker with the two inlets of the ground three-way gate valve [19]. The outlet of the threeway gate valve is connected to the inlet of the ground electric regulating valve through a short delivery pipe. The inlet of the ground electric regulating valve is connected to the inlet of the long-distance conveying pipeline. The long-distance transmission pipeline is laid along the surface, drilled on the ground to the underground roadway, and laid along the roadway floor to the underground area to be injected. The outlet of the long-distance transmission pipeline is connected with the inlet of the underground electric regulating valve, and the metal hose is connected with the outlet of the underground electric regulating valve as the output end of the liquid $\mathrm{CO}_{2}$ system. Pipeline pressure sensors, temperature sensors, and ultrasonic flow sensors are, respectively, installed at the input and output ends of the long-distance transportation pipeline. Carbon dioxide sensors are arranged along the long-distance transportation pipeline. The number of installations is determined according to the actual situation. The safe monitoring substations are installed near the input end and output end of the long-distance transportation pipeline and are connected to the electric regulating valve, pipeline pressure sensor, temperature sensor, ultrasonic flowmeter, and carbon dioxide sensor by utilizing the mine communication optical cable. The mine communication cable is utilized to connect the underground mine safe monitoring substation to the 
TABLE 2: Peak temperature and maximum DSC value under experimental conditions 1-4 (Table 1).

\begin{tabular}{lcr}
\hline & Peak temperature $\left({ }^{\circ} \mathrm{C}\right)$ & Maximum DSC value $(\mathrm{W} / \mathrm{g})$ \\
\hline 1 & 460.148 & 12.025 \\
2 & 461.673 & 12.004 \\
3 & 467.533 & 11.663 \\
4 & 471.874 & 11.471 \\
\hline
\end{tabular}

TABLE 3: Basic model parameters.

\begin{tabular}{lcc}
\hline & Model parameters & Parameter values \\
\hline 1 & Working face & Length $306 \mathrm{~m} \times$ width $5 \mathrm{~m} \times$ height $5.6 \mathrm{~m}$ \\
2 & Intake airway & Length $20 \mathrm{~m} \times$ width $5.5 \mathrm{~m} \times$ height $4 \mathrm{~m}$ \\
3 & Return airway & Length $20 \mathrm{~m} \times$ width $5 \mathrm{~m} \times$ height $4 \mathrm{~m}$ \\
4 & Goaf & Length $300 \mathrm{~m} \times$ width $306 \mathrm{~m} \times$ height $15 \mathrm{~m}$ \\
5 & Mean inclination & $1-3^{\circ}$ \\
6 & Pipe diameter & $60 \mathrm{~cm}$ \\
7 & Depth of buried pipes & $80 \mathrm{~m}, 100 \mathrm{~m}$, and $120 \mathrm{~m}$ \\
\hline
\end{tabular}

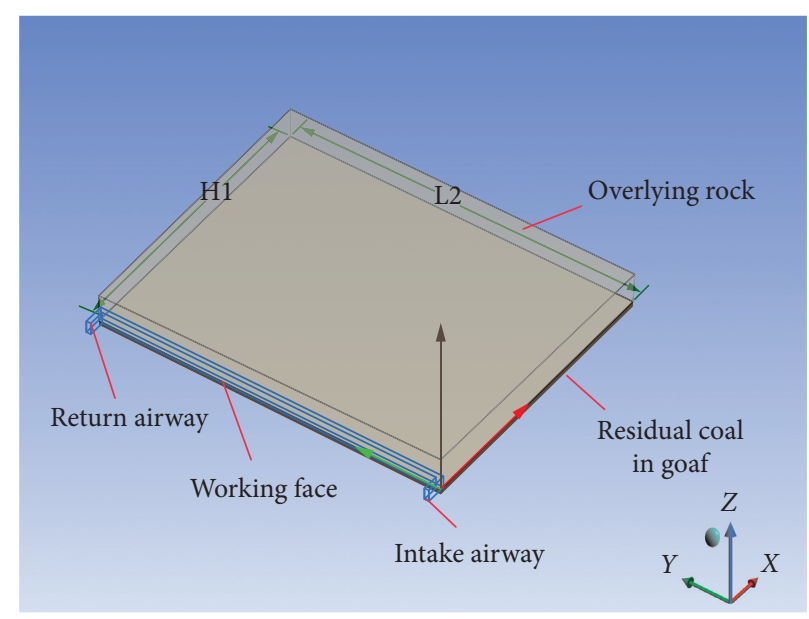

Figure 13: Geometric description of the model.

TABle 4: Values of density, specific heat, and thermal conductivity for model materials.

\begin{tabular}{lccc}
\hline & Density $(\mathrm{kg} / \mathrm{m})$ & Specific heat $(\mathrm{J} /(\mathrm{kg} \cdot \mathrm{K}))$ & Thermal conductivity $\left(\mathrm{m}^{2} / \mathrm{s}\right)$ \\
\hline Coal body & 1350 & 1250 & 0.15 \\
Rock mass & 1650 & 1650 & 0.2 \\
$\mathrm{CO}_{2}$ & 1.78 & 840 & $1.45 \times 10^{-7}$ \\
$\mathrm{O}_{2}$ & 1.43 & 920 & $2.5 \times 10^{-6}$ \\
$\mathrm{~N}_{2}$ & 1.138 & 1040 & 0.0242 \\
\hline
\end{tabular}

TABLE 5: Boundary control conditions of the model.

\begin{tabular}{lccccc}
\hline & Type & Numerical value & Temperature & Hydraulic diameter & Turbulence intensity \\
\hline Ventilation inlet & Inlet velocity & $0.2,0.5,0.8,1.0 \mathrm{~m} / \mathrm{s}$ & $300 \mathrm{~K}$ & $4.53 \mathrm{~m}$ & $15 \%$ \\
Ventilation outlet & Free overflow & 0.85 & - & - & - \\
$\mathrm{CO}_{2}$ inlet & Inlet mass flow & $9,18,27 \mathrm{t} / \mathrm{h}$ & $233 \mathrm{~K}$ & $0.6 \mathrm{~m}$ & $10 \%$ \\
\hline
\end{tabular}


underground fiber switch and connect the ground integrated control terminal to the underground fiber switch [20].

The system works as follows. The three-way gate valve to the gas phase end of the liquid $\mathrm{CO}_{2}$ tank is opened, and the ground and underground electric regulating valves are opened as well. Gaseous $\mathrm{CO}_{2}$ is utilized to dispose of the gas in the long-distance transmission pipeline, purging and exchanging gas for 10 minutes. The downhole electric regulating valve is closed to continuously increase the pressure of the long-distance transmission pipeline to $1.8-2.0 \mathrm{MPa}$, and the ground electric regulating valve is closed to ensure the desired value of pressure for $20 \mathrm{~min}$. According to the data changes of pressure sensor, ultrasonic flowmeter, temperature, and $\mathrm{CO}_{2}$ sensor, the air tightness of long-distance transportation pipeline can be evaluated. The three-way gate valve to the liquid end of the liquid $\mathrm{CO}_{2}$ tank is opened; the ground electric control valve is opened as well; and the underground electric control, the pressure sensor of the conveying pipeline, the ultrasonic flowmeter, and the temperature sensor start working. The feedback data is used to intelligently adjust the opening and closing state of the downhole electric control valve, to ensure that the pressure in the long-distance transportation pipeline is maintained at 1.8-2.0 MPa. Liquid carbon dioxide is injected into the target area through the metal hose at the output end, achieving long-distance intelligent pressure-holding transportation of liquid $\mathrm{CO}_{2}$. When any $\mathrm{CO}_{2}$ sensor along the long-distance transportation pipeline detects carbon dioxide in a concentration exceeding the set limit (in the intake air flow of the mining face, it is $0.5 \%$, and the other area limit settings refer to the relevant regulations of coal mine safety), or when the pressure sensor drops significantly close to the limit (the pipeline pressure limit is zero), the system automatically closes the ground and underground electric three-way gate valves and intelligently locks. After direct injection of liquid $\mathrm{CO}_{2}$ is completed, the three-way gate valve is opened to the gas phase end of the liquid $\mathrm{CO}_{2}$ tank, and the ground and underground electric regulating valves are opened as well. Gaseous $\mathrm{CO}_{2}$ is utilized to dispose of the gas in the longdistance transmission pipeline to ensure that the longdistance transmission pipeline is not blocked by dry ice. The air is purged for 10 minutes, the ground and underground electric regulating valves are closed, and the cleaning work of the long-distance transmission pipeline is completed [21].

\section{Field Tests of Direct Injection of Ground Liquid $\mathrm{CO}_{2}$}

6.1. Description. The field where the experiments have been carried out is now briefly described. There are 4 fully mechanized caving working faces, i.e., 202\#, 204\#, 206\#, and 208\#, in 12\# lower seam located in the lower layer of the southern wing of Huojitujing 12\# coal seam complex in Daliuta Coal Min. The working face is generally arranged along the inclination of the coal seam and advances along the strike. Directly above the working face is the goaf upper layer of the 12\# coal seam area. The interval between layers is
$1.5-4.7 \mathrm{~m}$. The upper layer working face has a mining height of 3.5-4.0 m. Stopping was completed in 2005. The layout of 206\# working face of $12 \#$ lower coal seam is shown in Figure 16, and the test was carried out in September 2018. A scheme of the process is illustrated in Figure 17.

The target area for direct injection of liquid $\mathrm{CO}_{2}$ is 206\# deep gob in 12\# lower coal seam. The surface power and water supply holes in the cutting hole area are utilized as drill holes. The surface of the borehole is used as system installation site, the power supply hole is used as vertical transmission hole for liquid $\mathrm{CO}_{2}$, and the low-temperature high-pressure resistant pipeline is about $84 \mathrm{~m}$ long. It is connected by a special welding method to the surface pressure-holding device and to the surface liquid $\mathrm{CO}_{2}$ tank through an austenitic metal body hose. The downhole direct injection pipeline is connected with the end of the ground drilling straight pipe through an austenitic metal hose. The terminal is connected to a long-distance automatic pressureholding device, and the austenitic metal hose is connected to the observation hole through the roof of the tunnel. Arched steel plates and expansion screws are installed. Warning signs are installed to ensure safety. The monitoring substation is installed as well; $1500 \mathrm{~m}$ communication optical fiber is laid, to connect computers by means of a ring network. The signal line starts from the substation and connects the pipeline pressure-holding device, the $\mathrm{CO}_{2}$ sensor, and the ground and surface pipes through the water supply drilling. The length of the signal line is about $1200 \mathrm{~m}$ for the connection of the pressure-holding device at the road terminal.

During the direct injection of liquid $\mathrm{CO}_{2}$, a value of $300 \mathrm{~m}^{3} / \mathrm{min}$ for the safe ventilation flow rate has been calculated and adopted, taking into account the limits of safe concentration of $\mathrm{CO}_{2}$ in a workplace.

6.2. Data Analysis. Liquid $\mathrm{CO}_{2}$ was infused for 3 hours (from 14:00 $\mathrm{h}$ to $17: 00 \mathrm{~h}$ ). The cumulative infusion amount was $60 \mathrm{t}$. The perfusion flow was $17.14-20.96 \mathrm{t} / \mathrm{h}$. Gas in the 206\# goaf of 12\# lower coal seam was collected and analyzed in real time through the fire prevention monitoring and control system. Figure 18 illustrates the variation in time for $\mathrm{O}_{2}$ and $\mathrm{CO}_{2}$ concentration with reference to 4 observation holes.

As far as observation point 29\# is concerned, $\mathrm{O}_{2}$ concentration only little changed upon $\mathrm{CO}_{2}$ injection, and gaseous $\mathrm{CO}_{2}$ concentration fluctuated between $0 \%$ and $5 \%$. At 09:00 $\mathrm{h}$ of the day after the day of the test, the $\mathrm{O}_{2}$ concentration in this area rose, and the gaseous $\mathrm{CO}_{2}$ concentration in the goaf was zero. The reason may be the solidification of liquid $\mathrm{CO}_{2}$ and the blockage of the bundle pipes by dry ice, causing only a small amount of gas to flow into the goaf, so these data are not meaningful for reference.

We now discuss data at observation point 30\#. The $\mathrm{O}_{2}$ concentration at the beginning of the injection dropped to zero, indicating that the area where liquid $\mathrm{CO}_{2}$ is injected is filled and made inert. Until 09:00 h of the subsequent day, $\mathrm{O}_{2}$ concentration fluctuated. At 11:00 h of this day, $\mathrm{O}_{2}$ concentration in the goaf rose to more than $15 \%$, indicating that, 


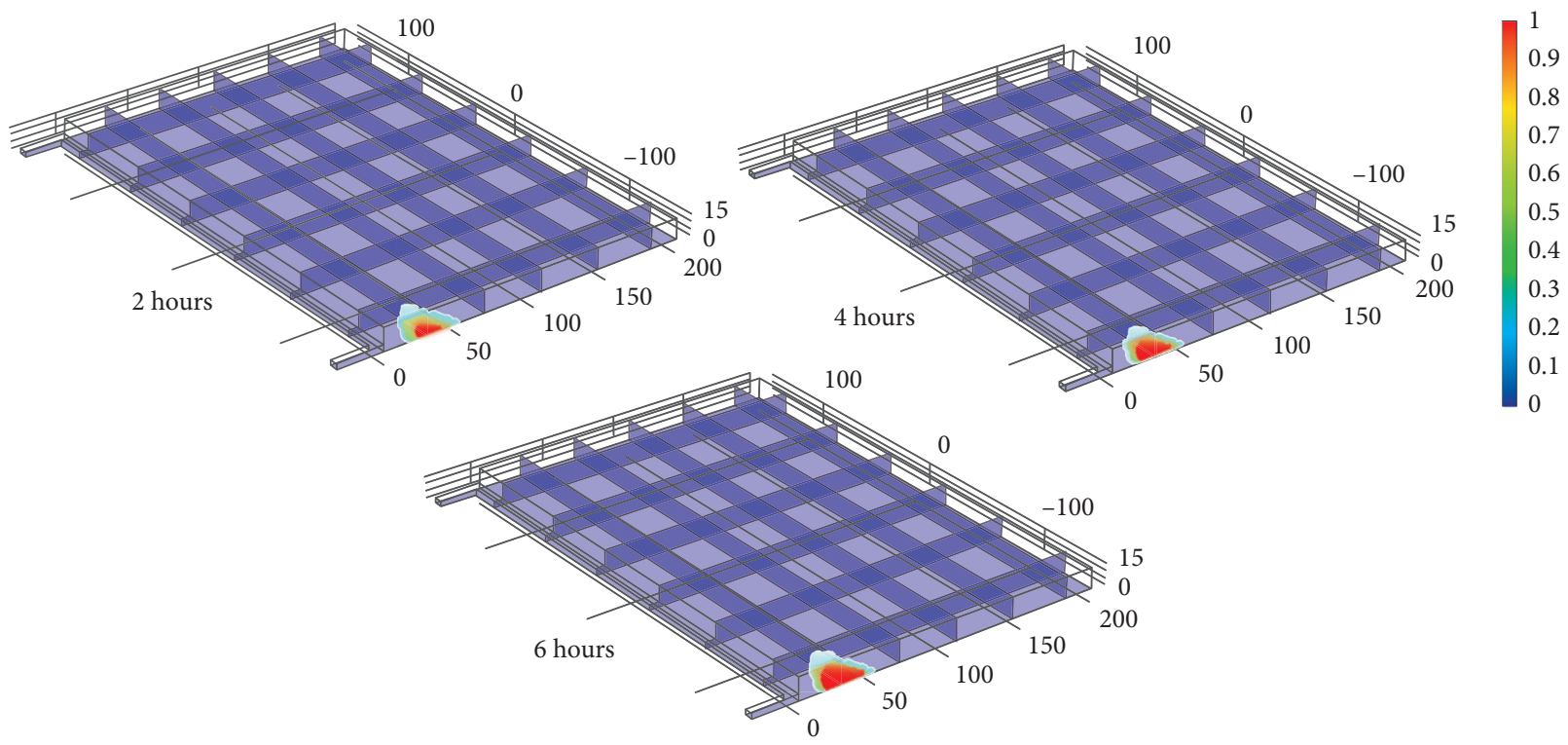

(a)

$60 \mathrm{~m}$

Mass fraction of $\mathrm{CO}_{2}$
\begin{tabular}{|l}
$1.00 e+00$ \\
$9.50 e+01$ \\
$9.00 e+01$ \\
$8.50 e+01$ \\
$8.00 e+01$ \\
$7.50 e+01$ \\
$7.00 e+01$ \\
$6.50 e+01$ \\
$6.00 e+01$ \\
$5.50 e+01$ \\
$5.00 e+01$ \\
$4.50 e+01$ \\
$4.00 e+01$ \\
$3.50 e+01$ \\
$3.00 e+01$ \\
$2.50 e+01$ \\
$2.00 e+01$ \\
$1.50 e+01$ \\
$1.00 e+01$ \\
$5.00 e+02$ \\
$0.00 e+00$
\end{tabular}

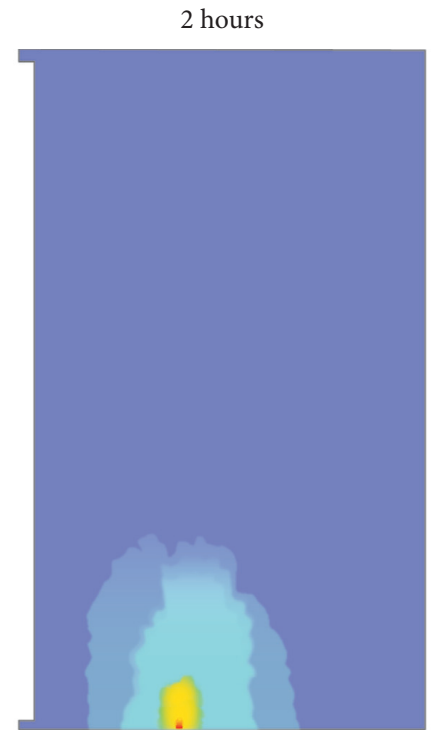

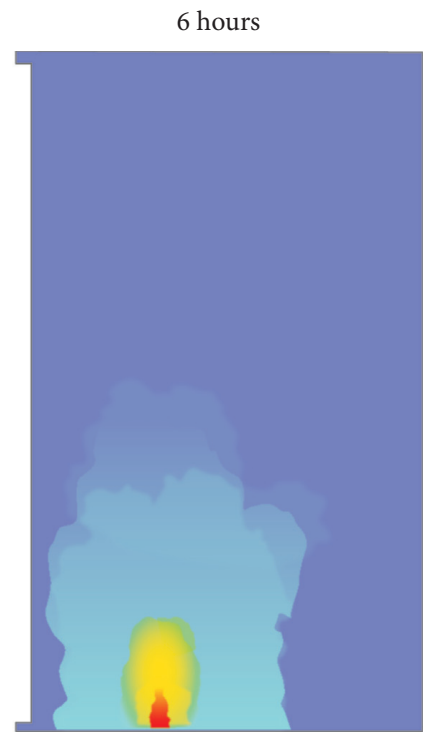

(b)

Figure 14: $\mathrm{CO}_{2}$ distribution characteristics during 6-hour injection. (a) Three-dimensional simulation of carbon dioxide diffusion. (b) Plane simulation diagram of carbon dioxide diffusion.

under the positive pressure of mine ventilation, gaseous $\mathrm{CO}_{2}$ in the goaf was exhausted; during the entire process, the $\mathrm{CO}_{2}$ concentration was zero as the gaseous $\mathrm{CO}_{2}$ monitoring range of the fire prevention system is $0-20 \%$, so higher concentration of $\mathrm{CO}_{2}$ put the detector out of service.

As far as observation point 31 \# is concerned, it can be seen that the goaf area is affected by liquid $\mathrm{CO}_{2}$ infusion. $\mathrm{O}_{2}$ concentration fluctuated between $14 \%$ and $16 \%$, and gaseous $\mathrm{CO}_{2}$ concentration between $2.0 \%$ and $3.31 \%$. At $11: 00 \mathrm{~h}$ of the subsequent day, $\mathrm{O}_{2}$ concentration rose to above $15 \%$, and gaseous $\mathrm{CO}_{2}$ concentration in the goaf was zero.

The last observation point is $32 \# . \mathrm{O}_{2}$ concentration fluctuated between $14 \%$ and $16 \%$, and gaseous $\mathrm{CO}_{2}$ concentration between $1 \%$ and $2.55 \%$. At $11: 57 \mathrm{~h}$ of the subsequent day, gaseous $\mathrm{CO}_{2}$ concentration was zero. This area was less affected by liquid $\mathrm{CO}_{2}$ infusion.

At the same time, in order to investigate the intelligent locking performance of the equipment during the longdistance pressure-holding transportation process of ground liquid $\mathrm{CO}_{2}$, during the continuous infusion period, a pulsed gaseous $\mathrm{CO}_{2}$ release device was used, and the release location was selected to lay the long-distance transportation pipeline. The carbon dioxide sensor hanging on the roadside detected the gaseous $\mathrm{CO}_{2}$ with a content of $0.8 \%$, the system was intelligently locked, and the ground control terminal sent out prompt warning. 


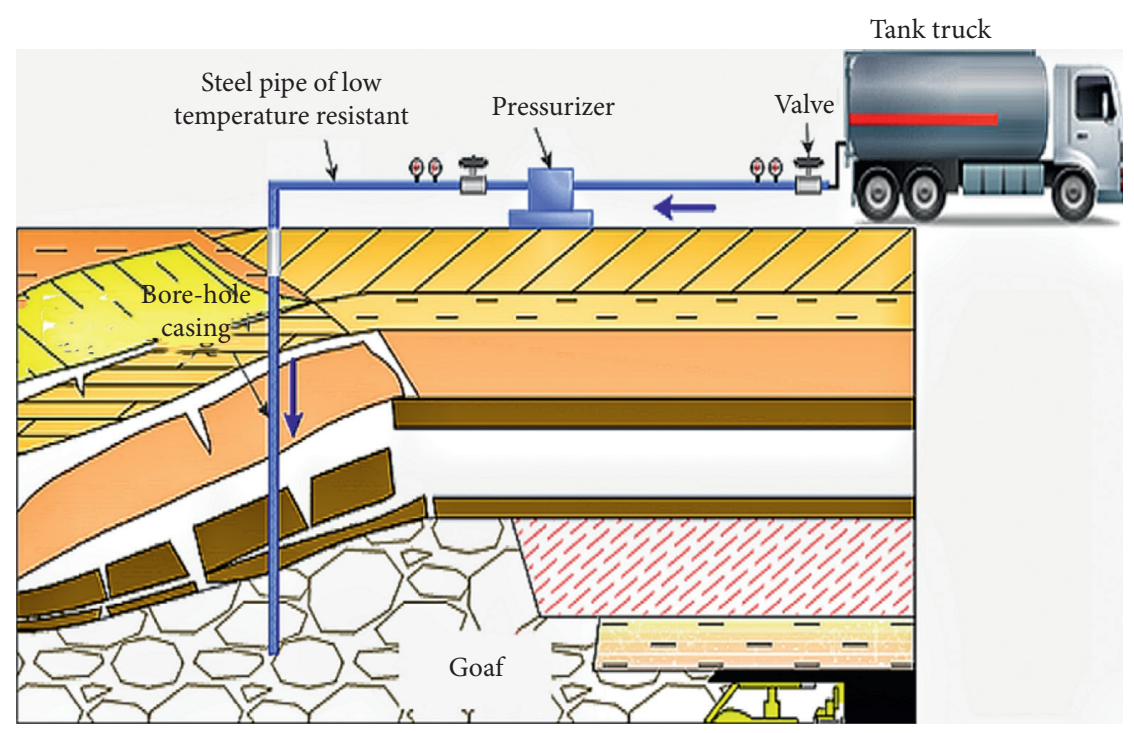

Figure 15: Schematic diagram of the proposed process for surface liquid $\mathrm{CO}_{2}$ direct injection.

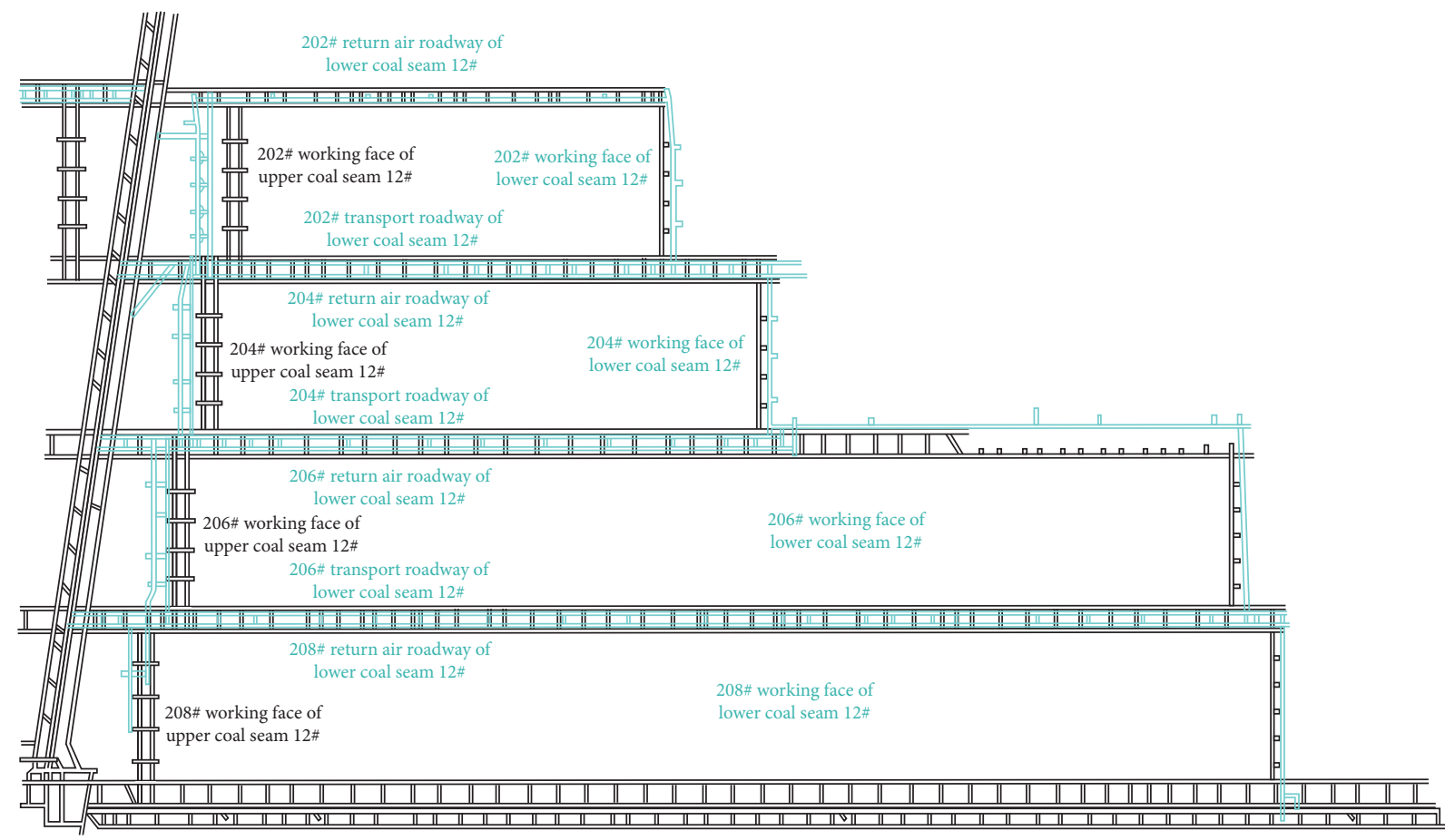

Figure 16: Layout of 206\# working face of 12\# lower coal seam.

6.3. Fire Prevention Effect. The actual daily advancing speed of 206\# working face of 12 \# lower coal seam in Huojitujing well of Daliuta Coal Mine in Shendong mining area is less than $1 \mathrm{~m}$, and it has not therefore reached the designed daily advancing speed of $2 \mathrm{~m}$. Due to faults and floor swelling during the mining process, the working face did not reach the predicted advancing speed, which created conditions for oxidation and spontaneous combustion of the remaining coal. On a particular day, the CO concentration in the working face sharply rose, thus highlighting the possibility of spontaneous combustion in the goaf. When the air flow rate in the fully mechanized caving face equals $1020 \mathrm{~m}^{3} / \mathrm{min}$, the $\mathrm{CO}$ concentration in the upper corner is, in regular conditions, $2 \mathrm{ppm}$. At 07:33 h of that day, the upper corner $\mathrm{CO}$ sensor raised the alarm with a concentration of $28.5 \mathrm{ppm}$; at 07:43 h, the return air CO sensor raised the alarm with a concentration of $37.5 \mathrm{ppm}$; and at $07: 55 \mathrm{~h}$, the return air outlet CO sensor raised the alarm with a concentration of $73.75 \mathrm{ppm}$. A gas sample was taken from the ground through a $30 \#$ observation hole (observation point $30 \#$ ), and it was 


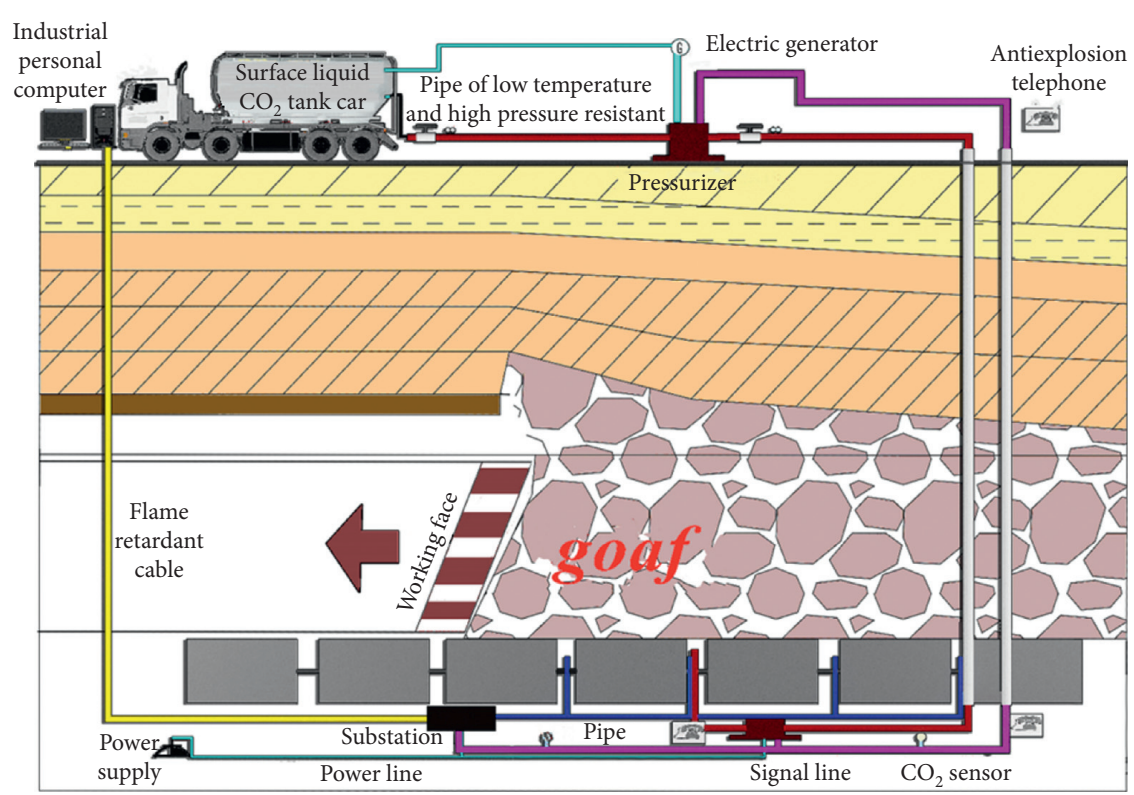

FIgUre 17: Process scheme of ground liquid $\mathrm{CO}_{2}$ direct injection.

found that the concentration of $\mathrm{CO}$ was $800 \mathrm{ppm}$; 9 hours later, the concentration of $\mathrm{CO}$ rose to $1000 \mathrm{ppm}$. The spontaneous combustion of the leftover coal in the goaf switched from the slow to the rapid oxidation stage and began to enter the spontaneous combustion stage, which is enough to indicate that there is a fire in the goaf. Ethylene and acetylene were not seen in the fully mechanized caving face and its upper and lower troughs and gas drainage pipelines. Therefore, the fire did not yet fully enter the combustion stage and no open flame appeared.

In order to obtain the best fire prevention effect, it is advisable to locate the release port in the natural oxidation zone of the goaf. This moves forward along with the working face, so the buried pipe for inert gas injection should be also moved forward regularly.

The design value for gaseous $\mathrm{CO}_{2}$ injection volume is calculated according to

$$
V_{\mathrm{CO}_{2}}=W \cdot H \cdot L \cdot K_{1} \cdot K_{2},
$$

where $W$ is the inerting zone width $(50 \mathrm{~m}), H$ its height $(1.6 \mathrm{~m})$, and $L$ its length $(155 \mathrm{~m}) ; K_{1}$ is the gas displacement coefficient in the goaf (2.5); and $K_{2}$ is the loose factor of the goaf (0.85). It is $V_{\mathrm{CO}_{2}}=26350 \mathrm{~m}^{3}$ [22].

The air leakage flow velocity in the goaf spontaneous combustion zone is $v=0.1-0.2 \mathrm{~m} / \mathrm{min}$ (average: $0.15 \mathrm{~m} /$ $\mathrm{min})$. The cross-sectional area through the fire zone is $S=W \cdot H=60 \mathrm{~m}^{2}$. Then, the flow rate of $\mathrm{CO}_{2}$ leakage is $\nu \cdot S=$ about $13000 \mathrm{~m}^{3}$ per day.

The daily gas injection volume of carbon oxide was therefore $13000 \mathrm{~m}^{3}$. The amount of normal gas per ton of liquid $\mathrm{CO}_{2}$ vaporized is estimated at $550 \mathrm{~m}^{3}$, and the amount of liquid $\mathrm{CO}_{2}$ required per day is therefore $24 \mathrm{t}$.

The pressure of the $\mathrm{CO}_{2}$ release port at the end of the pipeline should not be lower than $0.1-0.2 \mathrm{MPa}$, so that the outlet is always in the spray state to improve the inerting effect.
Two injections, each of about $20 \mathrm{t}$ liquid $\mathrm{CO}_{2}$, were performed. The second injection took place after $25.5 \mathrm{~h}$ with respect to the first one. The CO concentration in goaf near observation point $30 \#$ is reported as a function of time with reference to both liquid $\mathrm{CO}_{2}$ injections in Figure 19. This concentration began to gradually decrease after a delay of 2.5 hours from the beginning of the first injection. It then dropped from $790 \mathrm{ppm}$ to $140 \mathrm{ppm}$ during the first liquid $\mathrm{CO}_{2}$ injection. Then, the second injection took place (the initial value of the CO concentration $=140 \mathrm{ppm}$ ). The pattern of CO concentration is now hump-like; CO concentration "rebounds" with a maximum value not higher than $180 \mathrm{ppm}$ around $4 \mathrm{~h}$ after the beginning of the second stage. The reason is that, after the injection of carbon dioxide is stopped, the carbon dioxide located at the fire source diffuses to its surroundings, causing the $\mathrm{CO}_{2}$ concentration at the fire source to decrease. The final value of the $\mathrm{CO}$ concentration at the end of the second stage, whose duration is $16 \mathrm{~h}$, is $40 \mathrm{ppm}$.

\section{Discussion}

The adsorption, cooling, and diffusion of liquid $\mathrm{CO}_{2}$ in loose coal mines are analyzed through experiments that can provide a good theoretical basis for numerical simulation and industrial testing. The numerical software simulates the diffusion range of $\mathrm{CO}_{2}$ in the goaf, thereby verifying the experimental observation that the liquid $\mathrm{CO}_{2}$ has good diffusion properties. Based on the theoretical basis supported by the experimental data, industrial experiments are carried out, and the actual application effect of liquid $\mathrm{CO}_{2}$ in fire prevention and extinguishing is analyzed through the change in the concentration of the coal spontaneous combustion indicator (CO) in the on-site goaf. In this way, the correctness of the experimental theory is verified by practice.

$\mathrm{Ma}$ et al. studied the spontaneous combustion characteristic parameters of coal after $\mathrm{CO}_{2}$ adsorption [23]. In an 


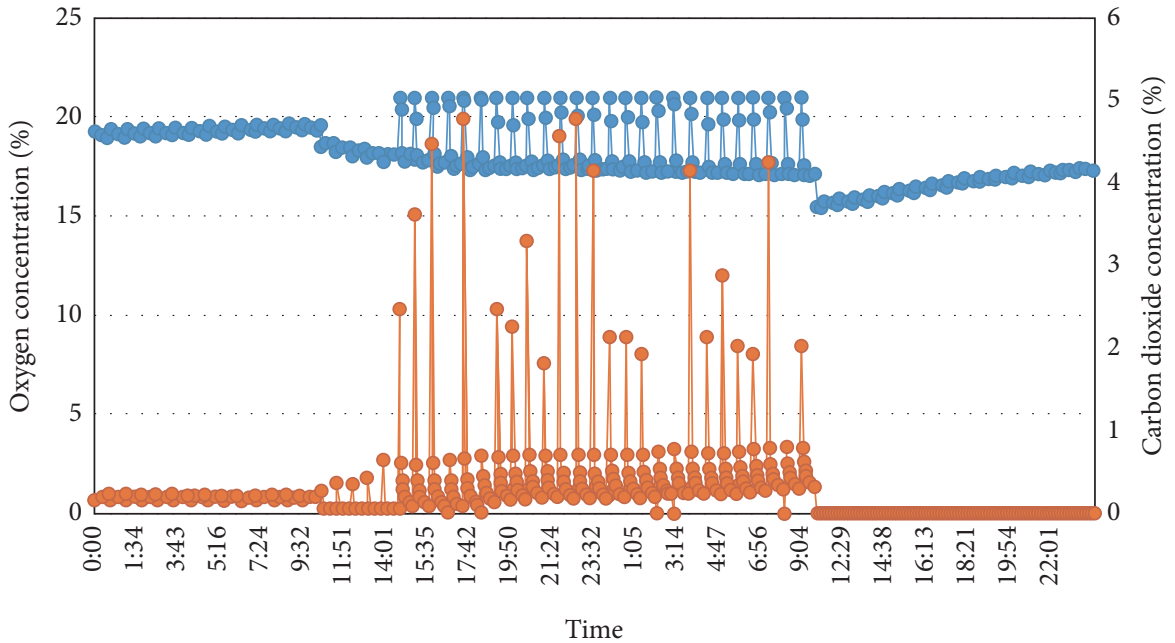

- $\mathrm{O}_{2}$ concentration

$-\bullet \mathrm{CO}_{2}$ concentration

(a)

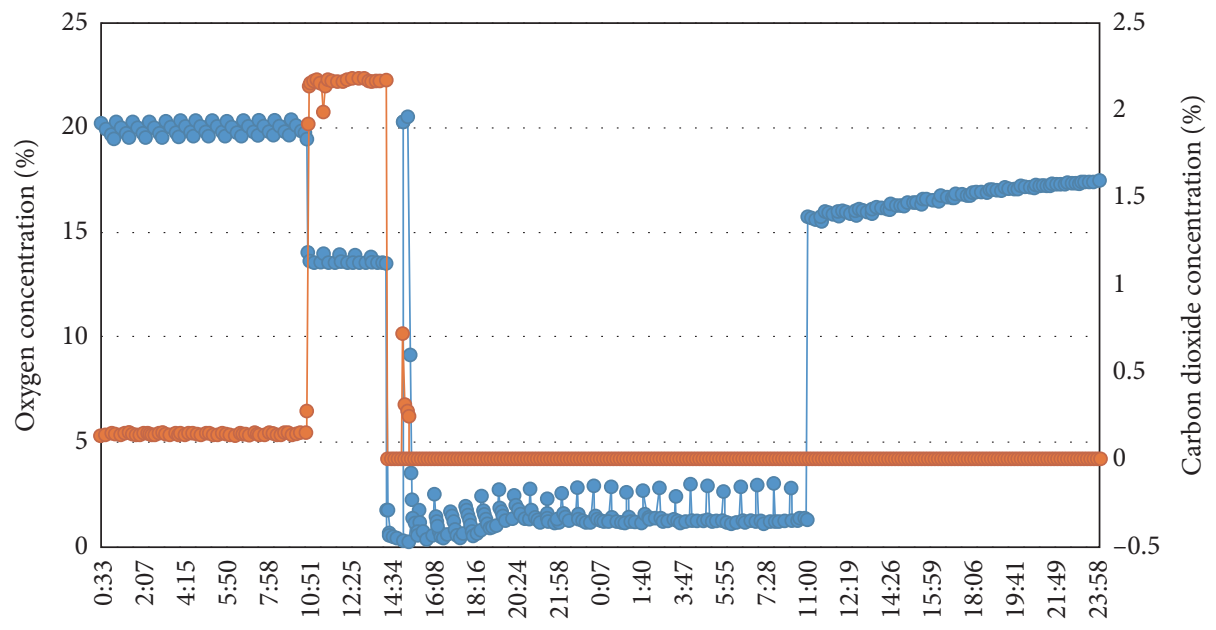

Time

$-\bullet \mathrm{O}_{2}$ concentration

$-\mathrm{CO}_{2}$ concentration

(b)

Figure 18: Continued. 


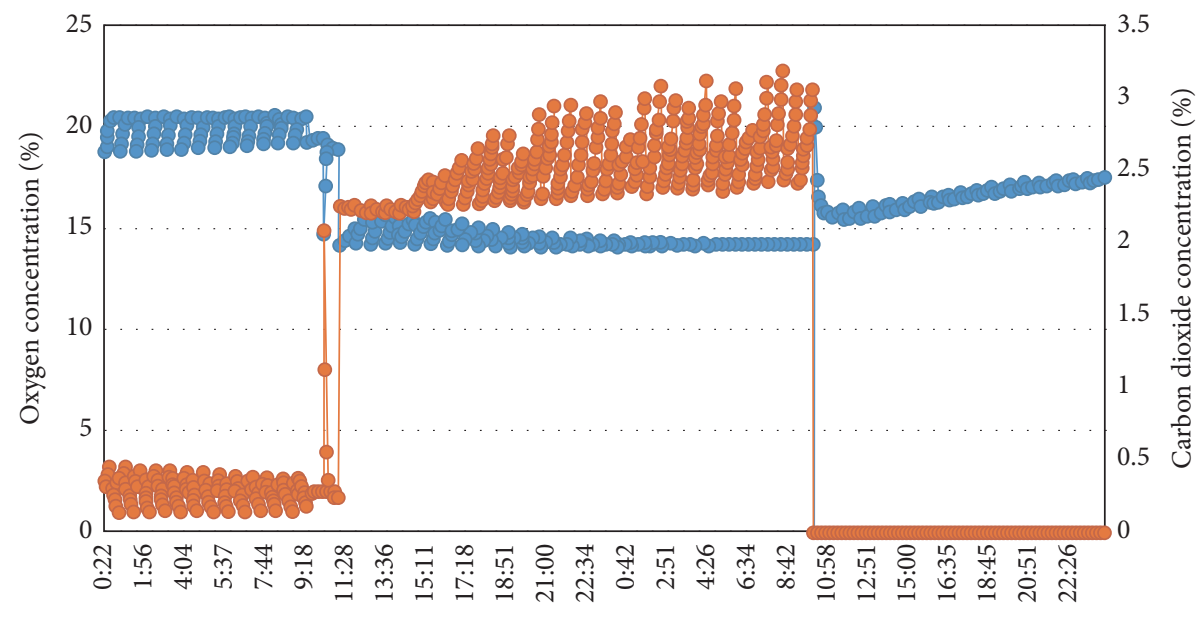

Time

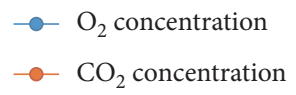

(c)

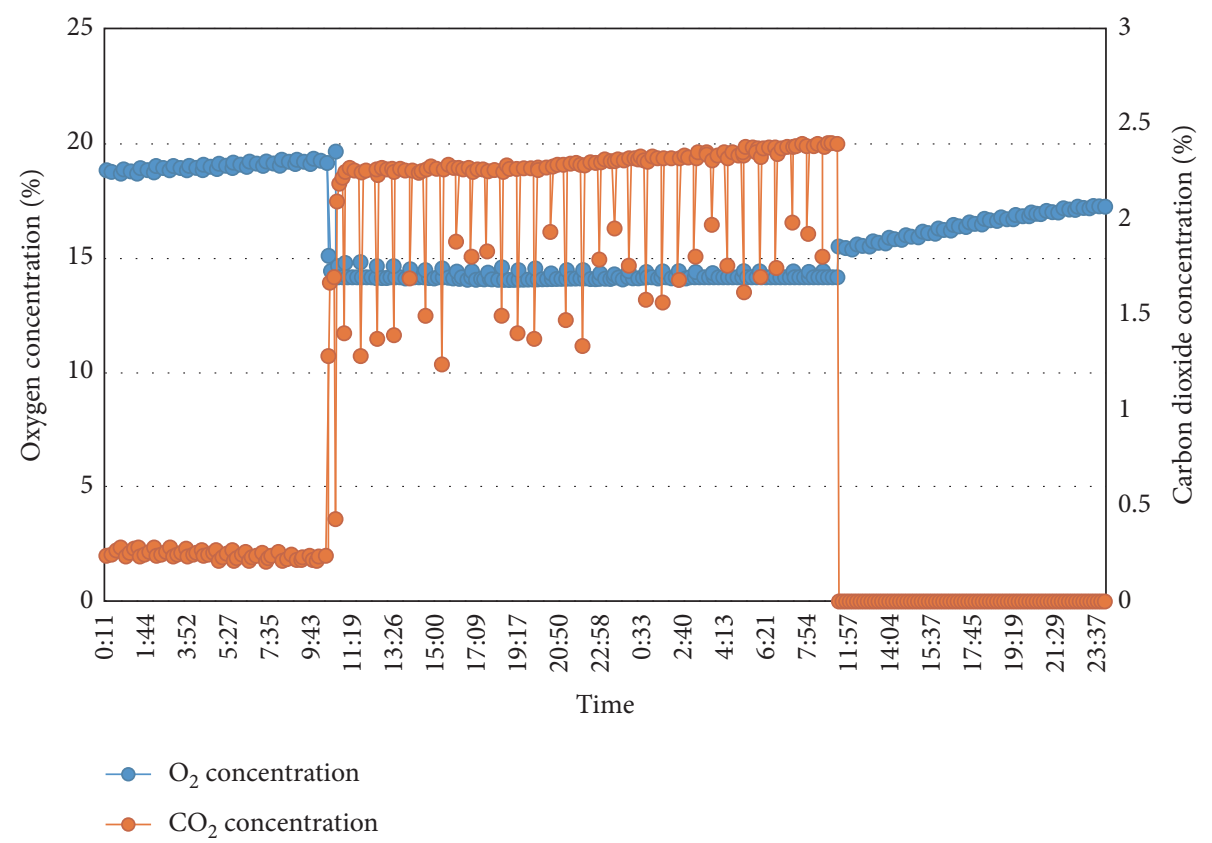

(d)

Figure 18: Variation in time of gaseous $\mathrm{O}_{2}$ and $\mathrm{CO}_{2}$ concentration upon tests of direct injection of $\mathrm{CO}_{2}$ in real field. Figures from top to bottom refer to four different observation points, named 29\#, 30\#, 31\#, and 32\#.

experiment about oxygen consumption characteristic during the coal heating process under atmosphere with different $\mathrm{CO}_{2}$ concentration, they observed that the activation energy of coal-oxygen reaction, after adding $\mathrm{CO}_{2}$, increases and the coal oxidation reaction rate correspondingly decreases. TGDTG-DSC was utilized to study the coal sample during the spontaneous combustion and oxidation process of three typical samples in four different atmospheres and different heating rates. The kinetic parameters for coal oxidation were calculated, and the influence of $\mathrm{CO}_{2}$ in inhibiting coal spontaneous combustion was determined. With the increase of $\mathrm{CO}_{2}$ concentration, the apparent activation energy and preexponential factor for coal oxidation reaction rapidly decrease, and the overall reaction rate and the heat release decrease as well. Zhang determined the distribution of the "three zones" of spontaneous combustion in the goaf after liquid $\mathrm{CO}_{2}$ injection and showed that these zones were redistributed, the heat dissipation zone was significantly shortened, and the oxidation zone moved forward [24].

Though showing relevant results, the above research has a limitation; that is, only the macroscopic analysis of the inerting effect of $\mathrm{CO}_{2}$ is investigated, while the mechanism 


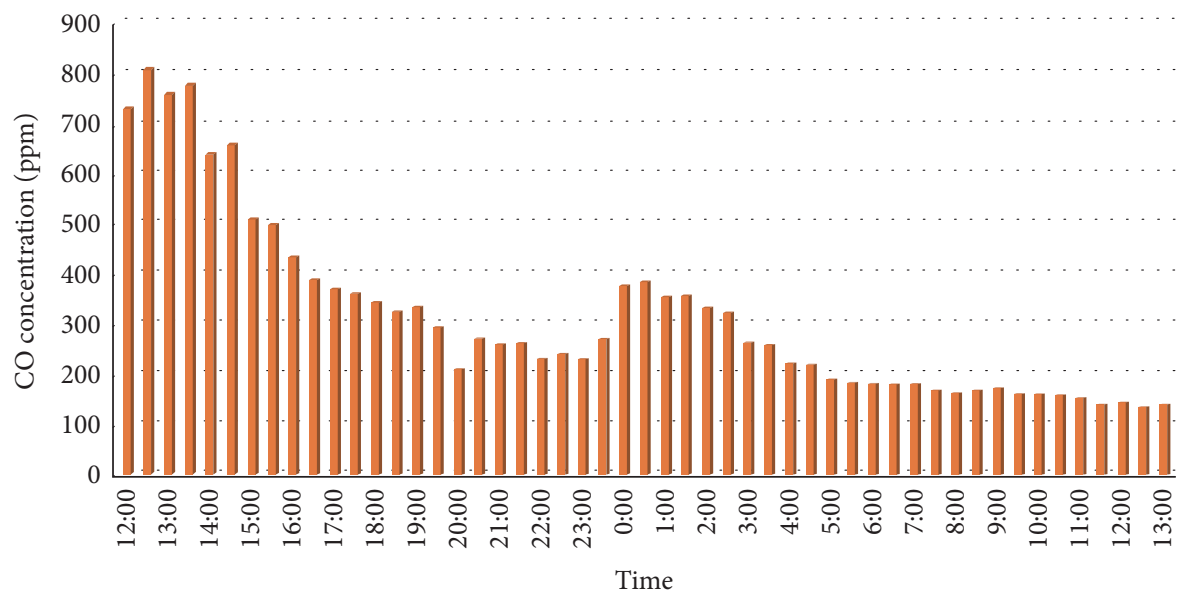

(a)

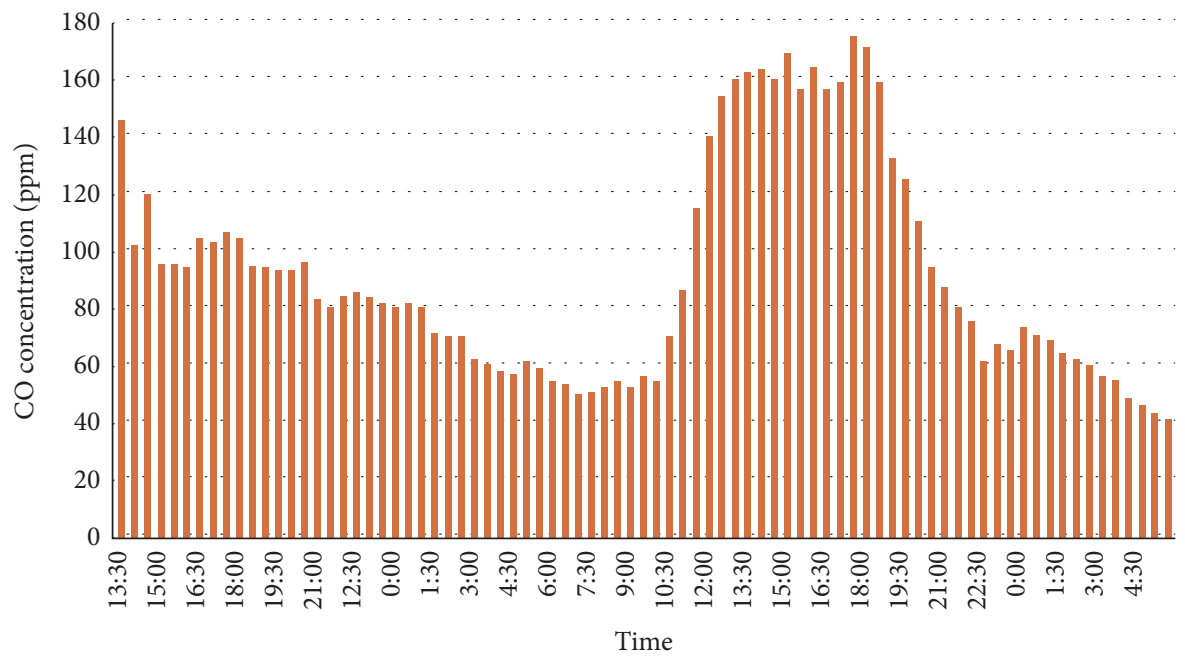

(b)

Figure 19: Variation of CO concentration during the first (top) and second (bottom) injection.

of $\mathrm{CO}_{2}$ in inhibiting the coal spontaneous combustion process is still worthy of investigation, as well as the temperature and concentration distribution in the goaf that need to be quantitatively studied and analyzed.

Accordingly, this project studies $\mathrm{CO}_{2}$ migration fire prevention characteristics in shallow buried near-horizontal goafs, including $\mathrm{CO}_{2}$ microscopic mechanism of inhibiting coal spontaneous combustion, core area of jet and phase change after $\mathrm{CO}_{2}$ is injected into the goaf, diffusion radius, effective inerting radius, cooling range, and cooling degree.

Zhao et al. studied the functional relationship between the flow rate and the temperature and pressure drop ratio when liquid $\mathrm{CO}_{2}$ steadily flows in the pipeline, and determined the limiting pressure drop ratio and critical flow rate for dry ice [25].

In the practice of liquid $\mathrm{CO}_{2}$ direct injection technology, as for the problem of short transportation distances, poor reliability of pressure-holding conveying can be observed, thereby being unable to realize real-time monitoring of pipeline fluid and environmental parameters. Accordingly, this project studies the appropriate liquid $\mathrm{CO}_{2}$ injection form, release port position, outlet pressure, release flow, and other process parameters, in order to form a perfusion capacity higher than $10 \mathrm{t} / \mathrm{h}$ at transportation distance longer than $800 \mathrm{~m}$. Field application and tests were conducted; the performance of each system and fire prevention technology were optimized and improved; and a liquid $\mathrm{CO}_{2}$ direct injection system with automatic pressure regulation, safety relief, automatic alarm, and lockout functions was developed, in order to achieve long-distance safe transportation of liquid $\mathrm{CO}_{2}$. However, there were still problems of limited liquid $\mathrm{CO}_{2}$ injection and short injection time. Due to limited budget, it was difficult to carry out large-scale and long-term perfusion tests to fill the entire composite mined-out area. Therefore, it was not possible to more accurately study the critical amount of liquid $\mathrm{CO}_{2}$ and the migration and diffusion radius that fill the entire goaf. Moreover, during the industrial tests carried out here, the gaseous $\mathrm{CO}_{2}$ monitoring range of the fire prevention monitoring system was $0-20 \%$ only. Therefore, higher values were not detectable, and the concentration change of the highly concentrated liquid $\mathrm{CO}_{2}$ near the direct injection port could not be monitored in real 
time. In addition, some monitoring beam tubes were blocked due to solidification of liquid $\mathrm{CO}_{2}$, which causes data distortion in some pipelines. Therefore, in the future, we will choose real mines with spontaneous fires to carry out large-flow and long-term liquid $\mathrm{CO}_{2}$ direct injection industrial tests, and choose a $\mathrm{CO}_{2}$ monitoring system with a larger monitoring range.

However, this project still brings economic and social benefits. This technology in fact uses liquid $\mathrm{CO}_{2}$ as a new fire prevention material under the possible coexistence of multiple types of fires such as those in mine coal field, small kiln, and multilayer mined-out and hidden high-temperature areas. Ensuring the safe mining of the working face can determine significant cost savings and, at the same time, protect mining operators. In addition, the use of liquid $\mathrm{CO}_{2}$ can have advantages in terms of reduction of greenhouse gas emissions.

The research content of the project meets the development requirements of sustainable strategies in coal industry and pushes forward the research direction and technical countermeasures for major coal mine fire safety. Technological market application prospects are broad, as the technical system plays a leading role in the related mine fire prevention technology and equipment.

\section{Conclusion}

In the coal cooling experiments, it was seen that larger coal particle sizes lead to better cooling effect. For coal samples in the same tank, those located in upper and middle positions show better cooling. The cooling of the coal samples can be roughly divided into three stages. The second and third stages are greatly affected by the particle size. The time occupied by the second stage decreases with the increase of the coal sample size, and the time occupied by the third stage correspondingly increases.

The critical temperature of the coal sample is $60-80^{\circ} \mathrm{C}$, and the dry cracking temperature is $100-130^{\circ} \mathrm{C}$. As the concentration of carbon dioxide and nitrogen increases, the concentration of oxygen decreases, and the characteristic temperature of the coal sample gradually increases; besides, when the oxygen concentration just begins to decrease, the characteristic temperature changes, which means that the characteristic temperature of the coal sample has an effect on $\mathrm{CO}_{2}$ concentration. The sensitivity decreases with increasing $\mathrm{O}_{2}$ concentration. At the same time, in the experiment with a higher amount of added $\mathrm{CO}_{2}$, the characteristic temperature of the coal sample is higher, the inerting effect on the coal sample is better, and the coal spontaneous combustion is less likely to occur. The oxygen consumption rate of the coal sample increases with the increase of the $\mathrm{O}_{2}$ concentration in the carrier gas during the oxidation and heating process.

The higher the $\mathrm{CO}_{2}$ concentration, the higher the peak temperature of the coal sample in the DSC experiment, but an inverse relationship with the maximum heat release rate is observed. At the same time, the apparent activation energy of coal samples increases as the $\mathrm{CO}_{2}$ concentration increases, and the sensitivity of the apparent activation energy of coal to the concentration of $\mathrm{CO}_{2}$ is different.
An intelligent pressure-holding transportation of liquid $\mathrm{CO}_{2}$ in the $1000 \mathrm{~m}$ transportation pipeline was developed. The surface liquid $\mathrm{CO}_{2}$ infusion capacity is $20 \mathrm{t} / \mathrm{h}$. The pressure-holding interval at the end of the transportation pipeline is determined to be $1-2.3 \mathrm{MPa}$. The maximum diffusion radius of the goaf is $300 \mathrm{~m}$. Under the influence of reverse wind flow and self-expansion and diffusion, the diffusion radius of the goaf is $150 \mathrm{~m}$. The maximum storage time of gaseous $\mathrm{CO}_{2}$ in the goaf is $27 \mathrm{~h}$.

Because the large amount of $\mathrm{CO}_{2}$ injected into the goaf is adsorbed by coal or dissolved by water, even under highintensity injection, the amount of emitted $\mathrm{CO}_{2}$ is not large, and the maximum concentration of $\mathrm{CO}$ in the working face and in the return air flow is only $0.03 \%$, which is within the limits. This can ensure the safety of the $\mathrm{CO}_{2}$ infusion working face.

In the case of a fire in the fully mechanized mining or caving face, as long as the oxidation and spontaneous combustion of coal has not developed to a rapid reaction stage, $\mathrm{CO}_{2}$ can prevent and extinguish the fire. The success or failure lies in the early detection of the fire. In case of fire and smoke, close measures should be taken immediately, and then the fire can be put out.

\section{Data Availability}

The data utilized to support the findings of this study are available from the corresponding author upon request.

\section{Conflicts of Interest}

The authors declare that they have no conflicts of interest.

\section{Acknowledgments}

The authors gratefully acknowledge the financial support from China Energy Investment Group Technology Innovation Program (SHGF-16-17(2016925489170)) and on-site technical guidance and treatment of problems from technical staff in Coal and Transportation Industry Management Department, China Energy Investment Group.

\section{References}

[1] Y. T. Liang, X. J. Hou, H. Z. Luo, F. C. Tian, and G. S. Yu, "Development countermeasures and current situation of coal mine fire prevention \& extinguishing in China," Coal Science and Technology, vol. 44, no. 6, pp. 1-13, 2016.

[2] Y. L. Ding, W. Dong, and J. Hao, "Fire prevention and control technology with sealing and liquid nitrogen injection during withdrawing period of coal mining face," Coal Science and Technology, vol. 41, no. 2, pp. 49-55, 2013.

[3] G. W. Gao, "The present state and prospects for nitrogen fireprevention and fire - elimination technology in coal mines of China," Journal of China Coal Society, vol. 24, no. 1, pp. 48-52, 1999.

[4] G. Y. Hu and L. Zhang, "Coal mine fire control in China," China Safety Science Journal, vol. 2, no. 1, pp. 11-19, 1992.

[5] B. Li, Research on Thermodynamic Characteristics and Heat Transfer Method of Uncontrolled Fire in Coal Gangue Dump, 
Xi'an University of Science and Technology, Xi'an, China, 2017.

[6] X. W. Zhai, Y. Xu, and Z. J. Yu, "Study on seepage law of $\mathrm{CO}_{2}$ in loose coal," Journal of Xi'an University of Science and Technology, vol. 38, no. 3, pp. 375-382, 2018.

[7] H. X. Guo and L. Mao, "Fire prevention and control technology of coal mining face in shallow depth and close distance easy spontaneous combustion coal seam group," Safety in Coal Mines, vol. 47, no. 2, pp. 148-154, 2016.

[8] G. H. Zhou, Study on the Mechanism of Preventing Coal Spontaneous Combustion with Liquid Carbon Dioxide and the Effective Fire-Fighting Technology in Goaf, Xi' an University of Science and Technology, Xi'an, China, 2019.

[9] X. W. Zhai and T. Y. Wang, "Experimental study on cooling laws of liquid $\mathrm{CO}_{2}$ on high temperature coal," Safety in Coal Mines, vol. 49, no. 4, pp. 30-33, 2018.

[10] Y. T. Liang, "Study on the characteristics of oxygen adsorption process of coal'," China Safety Science Journal, vol. 15, no. 1, pp. 71-73, 2005.

[11] Y. T. Liang, S. G. Wang, Y. Hu, S. Jiang, and S. L. Song, "Structure variation of coal particle packing during the spontaneous combustion," Journal of China Coal Society, vol. 45, no. 4, pp. 1398-1405, 2020.

[12] Y. Xiao, Z. P. Wang, L. Ma, and X. W. Zhai, "Research on correspondence relationship between coal spontaneous combustion index gas and feature temperature," Coal Science and Technology, vol. 36, no. 6, pp. 47-51, 2008.

[13] T. Liang and Z. Luo, "Experimental study on the free diffusing characteristics of oxygen in different granularity loose coal," Journal of China Coal Society, vol. 28, no. 5, pp. 470-472, 2003.

[14] L. Ma, Y. Y. Xing, and M. Wei, "Experimental study of coalbed methane replacement by injecting carbon dioxide," Safety in Coal Mines, vol. 49, no. 12, pp. 5-8, 2018.

[15] Z. Q. Tang, Pore Evolution during Coal Spontaneous Combustion Mechanism and its Effect on Multi-Gas Adsorption Characteristics, China University of Mining and Technology, Xuzhou, China, 2020.

[16] Z. G. Guo, Experiment Study on Temperature Rise Mechanism of Inert Gas Inhibiting Coal Spontaneous Combustion Oxidation, China University of Mining and Technology, Beijing, China, 2017.

[17] Y. P. Qin and J. Wang, "Coal particle gas desorption experiment and numerical simulation in enclosed space," Journal of China Coal Society, vol. 40, no. 1, pp. 87-92, 2015.

[18] Y. P. Qin and P. Liu, "Experimental study on gas adsorption law in coal particle and its numerical analysis," Journal of China Coal Society, vol. 40, no. 4, pp. 740-753, 2015.

[19] C. S. Zhang and X. H. Zhang, "fire prevention and extinguishing technology with canned liquid carbon dioxide," Journal of China Coal Society, vol. 47, no. 9, pp. 82-84, 2016.

[20] L. Ma, Y. Y. Xing, W. F. Wang, J. Deng Jun, and Z. P. Wang, "Simulation of application technological process of liquid carbon dioxide for goaf fire prevention and control," Journal of Xi'an University of Science and Technology, vol. 35, no. 2, pp. 152-158, 2015.

[21] G. Li, Study on Coal Spontaneous Combustion Law and Key Prevention Technology in Goaf under Condition of Gas Drainage, Shandong University of Science and Technology, Qingdao, China, 2019.

[22] Q.J. Shun and H. W. Yan, "Application of carbon dioxide fire prevention technology in goaf of Wenzhuang coal mine," Coal, vol. 9, no. 28, pp. 35-40, 2019.

[23] L. Ma, W. F. Wang, J. Deng, X. H. Zhang, and Z. P. Wang, "Effect of $\mathrm{CO}_{2}$ on characteristics of oxidation combustion for coal," Journal of China Coal Society, vol. 39, no. 2, pp. 397404, 2014.

[24] Zhang, Research on $\mathrm{CO}_{2}$ Prevention and Control Technology of Coal Mine Fire in Spontaneous Combustion and Gas Coal Seam Goaf, Taiyuan University of Technology, Taiyuan, China, 2015.

[25] Zhao, Throttling Process and Decompression Property for Pipeline Transportation of Anthropogenic $\mathrm{CO}_{2}$ in Different Phase, China University of Petroleum, Huadong, China, 2015. 